\title{
Numerical Simulation of Multi-Pass Parallel Flow Condensers with
}

\section{Liquid-Vapor Separation}

\author{
Nan Hua ${ }^{1,2}$, Huan $\mathrm{Xi}^{1,3}$, Rong $\mathrm{Ji} \mathrm{Xu}^{4}$, Ying Chen ${ }^{2^{*}}$, Hua Sheng Wang ${ }^{{ }^{*}}$ \\ ${ }^{I}$ School of Engineering and Materials Science, Queen Mary University of London, London, E1 4NS, UK, \\ ${ }^{2}$ Faculty of Materials and Energy, Guangdong University of Technology, Guangzhou, Guangdong \\ 510006, China, \\ ${ }^{3}$ Key Laboratory of Thermo-Fluid Science and Engineering of Ministry of Education, \\ School of Energy and Power Engineering, Xi'an Jiaotong University, Xi'an, Shaanxi 710049, China, \\ ${ }^{4}$ Beijing Engineering Research Center of Sustainable Energy and Buildings, Beijing University of Civil \\ Engineering and Architecture, Beijing, 100044, China,
}

\section{Abstract}

Liquid-vapor separation is an advanced technology recently developed enabling significant further heat transfer enhancement for condensers. This paper reports a distributed parameter model, using the $\varepsilon-N T U$ method, to numerically simulate heat transfer performance of multi-pass parallel flow condensers with liquid-vapor separation (referred to as MPFCs-LS). For achieving higher accurate results and lower computational time, a segment self-subdivision method is used to locate the positions of onset and completion of condensation. Furthermore genetic algorithm is adopted to determine the refrigerant flow rates through tubes in a flow pass. Relevant empirical correlations are selected for heat transfer and frictional pressure drop in different flow regimes during condensation in microfin tubes. The predictions of the model agree well with the experimental data within $\pm 20 \%$. The model and numerical methods developed in this work for MPFCs-LS are of important value in design and performance optimization of these new advanced condensers.

Keywords: Condensation heat transfer; Condenser; Liquid-vapor separation, Modelling; Numerical simulation; Genetic algorithm

2, *Corresponding author: Tel: +86 (0)20 39322572

E-mail chenying@gdut.edu.cn

$1,{ }^{*}$ Corresponding author: Tel: +44 (0)20 78827921

E-mail h.s.wang@,qmul.ac.uk 


\section{Introduction}

Refrigeration and air conditioning consume a huge amount of electricity, especially in summer. Design and optimization of refrigeration and air conditioning plants are therefore important in reduction of fossil fuel consumption and $\mathrm{CO}_{2}$ emission. In recent years, air-to-refrigerant condensers, as one of the key components in all these plants, have been extensively investigated. With the rapid development of computer and software, numerical simulations have been widely used due to their high efficiency and low cost, especially. Table 1 summarizes the numerical models that have been developed in recent six years for the numerical simulations of air-cooled heat exchangers [1-18].

Liquid-vapor separation technique applied in a slip type domestic air-conditioner system had been experimentally researched by Wu et al. [19] and Chen et al. [20-21]. After the replacement of a multi-pass parallel flow condenser with liquid-vapor separation (MPFC-LS), the heat transfer area of the condenser was reduced by $26.9 \%$ and the refrigerant charge amount of the system was $80.3 \%$ of the original one. This kind of condensers have multi-pass parallel flow configuration and used round tubes or microchannel tubes. In the tube side, tubes are divided into several passes separated by baffles in both headers. Compared with conventional multi-pass parallel flow condensers (MPFCs), the baffles separate condensate from the main stream. The baffles have purposely designed uniform-diameter orifices of approximately $0.5 \mathrm{~mm}$ to $2 \mathrm{~mm}$. When refrigerant at two phase flow into the intermediate header, the condensate accumulates on the baffle surface and forms a liquid film. The liquid film only allows the condensate to pass through the orifices due to the capillary force and pressure difference between the two sides of the baffle. The two-phase main stream with increased vapor quality flows into the next flow pass. This is the working 
principle of the liquid-vapor separation. The baffles serve as the liquid-vapor separators.

Hua et al. [1] proposed a lumped-parameter model of the MPFCs-LS. This model appears accurate, simplified and low computational cost and was used to optimise the tube-pass strategy of the condenser. Zhong et al. [22-25] implemented the same model to simulate the performance of single/duo-slab parallel flow microchannel condensers (PFMCs) with liquid-vapor separation. Luo et al. [26-27] applied the model for the optimization of the MPFCs-LS in organic Rankine circle.

Flow mal-distribution is important in design of heat exchangers. Zou et al. [28] and Byun and Kim [29] reported that the flow mal-distribution can result in up to $30 \%$ reduction in heat transfer. The mal-distribution of the refrigerant flow also exists in the MPFCs-LS. Therefore, flow mal-distribution should be considered in the design and modelling of the MPFCs-LS. For MPFCs with fixed geometries, the inlet pipe position and tube-pass configuration are the main parameters which effect the refrigerant flow distribution. For MPFCs-LS, the vapor quality after liquid-vapor separation is an additional parameter effecting the flow distribution. The design and arrangement of the orifices are hence important.

Some models have been developed to simulate the flow mal-distribution for the air-to-refrigerant heat exchangers. Domanski [30] proposed a public-domain tool, EVAP-COND, for the fin-tube heat exchangers. It establishes a tube by tube model and provides the simulation method for the refrigerant mal-distribution in circuits of different lengths based on the pressure balance principle i.e. pressure loss in each circuit must be added up to the same overall pressure drop. Similarly, Jiang et al. [31-32] developed the modeling software, CoilDesigner, to investigate the flow distribution of fin-tube heat exchangers. They used a distributed model, the same 
model for the round tube plate fin condenser by Joppole et al. [7]. The same principle, included the pressure losses in the headers, also applies to microchannel heat exchangers. Regarding the quality distribution, Liang et al. [9], Wang et al. [10] and Yin et al. [11] assumed that the refrigerant mass flow rate was evenly distributed among the flat tubes in the same tube pass. Zou et al. [5] built a mal-distribution model for the vapor quality distribution using the correlations based on the least-square curve-fit of their experimental data. Ablanque et al. [33] and Ren et al. [2] employed Hwang et al.'s [34] T-junction phase separation theory to predict the vapor quality distribution in each microchannel tube. Li and Hrnjak [8] presented infrared (IR) thermography to quantify the liquid mass flow rate through each flat tube using the corresponding measurable temperature difference in the air side. Zou et al. [15] modelled both round fin-tube and microchannel heat exchangers in humid air condition, using the method of Li and Hrnjak 8]. Some investigations (Huang et al. [4], Datta et al. [12] and Li et al. [16]) focused on the port-level modelling rather than the flat tube level modelling. For a given tube, the inlet air state at the first port is different from that at the last port along the air flow direction. This suggests that the heat transfer difference among air at different ports could induce flow mal-distribution in the refrigerant side. Moreover, some more-sophisticated models (Huang et al. [3] and Shojaeefard et al. [17-18]), so-called computational fluid dynamics (CFD) based co-simulation techniques, combined a detailed header simulation by CFD and one-dimension finite element model to simulate refrigerant flow and heat transfer in flat tubes.

With the requirement for more detailed characteristics or more effective factors of the performance of MPFCs-LS, improved models are needed. The present work will propose a distributed parameter model for flow mal-distribution of refrigerant 
condensates in the MPFCs-LS, base on the model of Hua et al. [1]. The distributed parameter model will be more accurate than the lumped parameter model. In addition, genetic algorithm (GA), a more efficient algorithm, will be introduced to calculate the refrigerant flow distribution profile at certain tube pass. The stability and convergence of the GA will be discussed.

Refrigerant flow in a condenser appears in vapor, two-phase and liquid. Those fluid properties and heat and mass transfer characteristics are significantly different. To enable high accuracy, first, a 'segment self-subdivision' approach will be proposed to track the phase change point in a segment. This approach has acceptable precision of prediction even at a lower number of discretised segments along the tubes, leading to much low computation time. In addition, the accuracy of model greatly depends on the correlations used. By identifying the flow-regimes, several correlations of heat transfer and frictional pressure drop of two-phase flow condensation will be compared. Finally, the model proposed for the MPFCs-LS will be verified with experimental data obtained in wide range of working conditions.

\section{Model of MPFC-LS}

A two-dimensional (2D) model is developed as shown in Fig. 1. The entire condenser is divided into three levels as:

1. Condenser level. The entire condenser is divided into tube passes separated by the baffles in the headers. The number of the tube pass is termed as NP.

2. Tube-pass level. A tube pass part consists of several branches i.e. tubes connecting to the headers at their two ends.

3. Branch level. Each branch consists of three types of elements: a dividing T-junction, a combining T-junction and tube cells. 
Each tube pass is labeled by $i$, which represents the $i$ th tube pass in the condenser along the refrigerant-flow direction. The heat transfer tubes are labeled by $i, j$, which represents the $j$ th tube in the $i$ th tube pass. The tube cells are labeled by $i, j, k . k$ represents the position of a tube cell i.e. $i, j, k$ referring to the current calculating position as the $k$ th segment of the $j$ th heat transfer tube in the $i$ th tube pass.

The mal-distributions appear as non-uniform distributions in refrigerant mass flow rate and vapor quality between tubes. For the mass flow rate mal-distribution, the refrigerant mass flow rates feeding in parallel tubes are inversely proportional to the pressure drops of the flow paths. The uneven vapor quality distribution results from factors such as the geometry of the headers, depth of the heat transfer tube protrusion, phase splitting in the headers, refrigerant and refrigerant mass flow rate. This paper refers to several studies on two-phase distribution in a header/branch tube configuration (Watanabe et al. [37]; Zou and Hrnjak [5]; Byun and Kim [38]), where experimental conditions and geometries limit the proposed correlations. In the present work the following two assumptions are made: (1) Owing to the characteristics of the liquid-vapor separation in the MPFCs-LS, the vapor qualities at the entrances of all tube passes, except the first tube pass and the sub-cooling regime, are assumed to be 1.0 ; (2) The refrigerant vapor quality is assumed to be evenly separated in branches. To simplify, the following assumptions are made:

(1) The fin-and-tube condenser operates in a steady state; (2) fins and headers are adiabatic; (3) the axial heat conduction in tubes is negligible; (4) the tube-wall temperature within a segment is uniform; (5) the properties of refrigerant and air within a segment are uniform; (6) both refrigerant flow and air flow are one-dimensional; (7) air flows through the heat exchanger straightly; (8) the flow is, thermally and hydro-dynamically, fully developed; (9) refrigerant is well-mixed in the 
intermediate headers; (10) the flow distribution in each tube-pass part is independent; (11) the inlet and outlet headers are simplified as series of dividing and combining T-junctions and the effects of recirculation and flow alterations transmitted among the adjacent junctions are ignored.

\subsection{Calculation method of heat transfer in control segment}

A one-dimensional (1D) finite segment approach is used to develop the model at the tube level. The heat transfer tubes of the condenser are divided into finite control segments along the refrigerant-flow direction. As shown in Fig. 2, each finite control segment is a tube-centered element, which can be treated as an independent cross-flow arrangement between air flow outside the tube and refrigerant flow inside the tube.

The conservation of mass, momentum and energy for the refrigerant flow inside tubes, including the superheated and sub-cooled single-phase flow and condensing two-phase flow, are given by Eqs. (1-3) below.

$$
\begin{gathered}
m_{\mathrm{r}}(i, j, k)=m_{\mathrm{r}}(i, j, k+1) \\
P_{\mathrm{r}}(i, j, k)=P_{\mathrm{r}}(i, j, k+1)+\Delta P_{\mathrm{f}, \mathrm{r}}(i, j, k)+\Delta P_{\mathrm{m}, \mathrm{r}}(i, j, k) \\
m_{\mathrm{r}}(i, j, k) h_{\mathrm{r}}(i, j, k)=Q(i, j, k)+m_{\mathrm{r}}(i, j, k+1) h_{\mathrm{r}}(i, j, k+1)
\end{gathered}
$$

The conservation of mass, momentum and energy for the air flow outside the tubes are given by Eqs. (4-6) below.

$$
\begin{gathered}
m_{\mathrm{a}}(i, j, k)=m_{\mathrm{a}}(i, j, k) \\
P_{\mathrm{a}, \text { in }}(i, j, k)=P_{\mathrm{a}, \text { out }}(i, j, k)+\Delta P_{\mathrm{f}, \mathrm{a}}(i, j, k) \\
m_{\mathrm{a}}(i, j, k) h_{\mathrm{a}, \text { in }}(i, j, k)+Q(i, j, k)=m_{\mathrm{a}}(i, j, k) h_{\mathrm{a}, \text { out }}(i, j, k)
\end{gathered}
$$

When Eqs. (1-3) are applied to the single-phase refrigerant flow region, the deceleration term $\Delta P_{\mathrm{m}, \mathrm{r}}(i, j, k)$ in Eq. (2) is neglected, Equations (2) and (3) can be 
solved independently. In the two-phase refrigerant flow region, since the saturation temperature determined by the pressure decreases due to the pressure drop, Eq. (2) and Eq. (3) are solved simultaneously. In the present model, the saturation temperature in a segment is assumed to be constant so that Eq. (3) is solved first and then Eq. (2). This assumption is appropriate when the segment is sufficiently small.

The logarithmic-mean-temperature-difference (LMTD) and $\varepsilon$-NTU methods are most commonly used to calculate the heat transfer between the refrigerant and air flows. Compared with the LMTD method, $\varepsilon-N T U$ method employs an iteration-free procedure that does not require the outlet conditions. The $\varepsilon-N T U$ method is therefore used in the present work. The cross-flow configurations are of the unmixed air stream and the mixed refrigerant flow:

$$
\begin{gathered}
c_{\text {mix }}(i, j, k)=m_{\mathrm{r}}(i, j, k) c_{p, \mathrm{r}}(i, j, k) \\
c_{\mathrm{unmix}}(i, j, k)=m_{\mathrm{a}}(i, j, k) c_{p, \mathrm{a}}(i, j, k) \\
c_{\text {max }}(i, j, k)=\max \left(c_{\text {mix }}(i, j, k), c_{\mathrm{unmix})}(i, j, k)\right) \\
c_{\text {min }}(i, j, k)=\min \left(c_{\text {mix }}(i, j, k), c_{\mathrm{unmix}}(i, j, k)\right)
\end{gathered}
$$

The heat transfer rate of the segment is calculated by

$$
Q(i, j, k)=\varepsilon(i, j, k) c_{\min }(i, j, k)\left(T_{\mathrm{r}}(i, j, k)-T_{\mathrm{a}, \mathrm{in}}(i, j, k)\right)
$$

When refrigerant appears single-phase flow in the segment,

$$
\varepsilon(i, j, k)=1-\exp \left(-\frac{c_{\max }(i, j, k)}{c_{\min }(i, j, k)}\left(1-\exp \left(-N T U(i, j, k) \frac{c_{\min }(i, j, k)}{c_{\max }(i, j, k)}\right)\right)\right.
$$

for $c_{\max }(i, j, k)=c_{\text {unmixed }}(i, j, k)$ and

$$
\varepsilon(i, j, k)=\frac{c_{\max }(i, j, k)}{c_{\min }(i, j, k)}\left(1-\exp \left(-\frac{c_{\min }(i, j, k)}{c_{\max }(i, j, k)}(1-\exp (-N T U(i, j, k)))\right)\right.
$$

for $c_{\text {max }}(i, j, k)=c_{\text {mixed }}(i, j, k)$.

When refrigerant appears condensing flow in the segment, 


$$
\varepsilon(i, j, k)=1-\exp (-N T U(i, j, k))
$$

188

189

190

191

192

193

194

195

where $N T U$ is defined as

$$
N T U(i, j, k)=\frac{U(i, j, k) \mathrm{A}}{c_{\min }(i, j, k)}
$$

The calculations of the heat-transfer coefficients at both refrigerant and air sides are important for the calculation of the overall heat-transfer coefficient, $U(\mathrm{i}, \mathrm{j}, \mathrm{k})$, in Eq. (15). Thus, it is very important to select appropriate correlations for the calculation of the heat transfer coefficients. Most of the simulators mentioned above just treat the two-phase refrigerant flow regime as annular flow regime, which is relevant to high vapor shear forces. But because of the specific tube pass arrangement and the tube of inner diameter $6.59 \mathrm{~mm}$, in the experimental range of the present work, a fair amount of the heat transfer tubes could be in the wavy and stratified flows regime which is dominated by gravity.

To obtain the amount of tubes in the wavy and stratified flows regime and identify the flow pattern, in present work, we modelled the test condenser roughly (arranging the tube-pass in $5 \rightarrow 3 \rightarrow 2 \rightarrow 1 \rightarrow 1 \rightarrow 1 \rightarrow 1$ ) based on the experimental inlet conditions. The calculated results are plotted in two flow pattern maps for condensation in microfin tubes. One is proposed by Thome et al [39-40], but the transition between intermittent flow and annular flow in which is replacing with new criteria developed by Liebenberg and Meyer's [41] for mirofin tubes. Another one is Doretti et al [42] modified based on the map of Tando et al. [43]. On the maps, a point represents a state of one heat transfer tube. The mass flux adopts the parameter of the refrigerant flow entering the parallel tubes from the dividing headers. The quality employs the average value between those of tube inlet and outlet.

As shown in Figs. 3 and 4, the flow pattern in the five tubes of the first tube-pass part in all cases are stratified-wavy, as well as appears in some of the tubes of the 
second tube-pass part in some cases. The heat transfer capacities of the first tube-pass are $400 \mathrm{~W}$ and $600 \mathrm{~W}$ while the total heat transfer capacities are $1125 \mathrm{~W}$ and $1525 \mathrm{~W}$, respectively, indicating that nearly $35 \%$ to $40 \%$ of the whole condenser heat transfer occurs in the flow regime dominated by gravity. The model developed in this work can be used for the optimisation of tube-pass arrangement in different inlet ranges, where the calculation conditions could be stricter. Thus, it is necessary to use the proper correlations for calculation of heat transfer and pressure drop in corresponding refrigerant flow regimes.

Therefore, two steps are implemented:

1. Identify the flow pattern of the two-phase refrigerant flow by Cavallini et al. [44] correlation;

2. For the stratified-wave flow regime: use separated heat transfer and frictional pressure drop correlations of the wavy and stratified flow proposed by Kim [45];

3. For the annular flow regime: evaluate some of the available classic heat transfer and frictional pressure drop correlations, recommended by Wang and Honda [46-47] for microfin tubes, based on the experimental data in this work.

All the correlations used in this investigation can be found in table 2 .

When the heat transfer in the annular flow regime is calculated with the $\varepsilon$-NTUs method, a temperature of tube-wall inner surface, $T_{\mathrm{w}, \text { inner }}(i, j, K)$, iteration should be introduced, as shown in Fig. 5. To enhance the computational efficiency, the calculations of the heat transfers in single phase and the stratified-wave flow regime could apply the iteration-free procedure.

\subsection{Determination of the locations of onset and completion of condensation}

Elemental heat exchanger models usually assume that refrigerant properties are 
constant in each element. When the calculation sequence matches the transition segment along the refrigerant flow direction, the correlations used to calculate the inlet condition of the segment are also used to calculate the phase-change part of the transition segment, resulting in over-prediction or under-prediction of the heat transfer capacity. Although this error can be reduced by increasing the number of the segments, the numerical solver can still be trapped at an unconverted point in the solution domain because of dual-value property functions. This problem can be worse in the $\varepsilon-N T U$ method compared with the LMTD method, because the dual-value property functions influence not only the calculation of the heat transfer coefficient at refrigerant side, but also the effectiveness, $\varepsilon$, equation. The detailed discussion of this is given in Iu et al. [60].

Many researchers made efforts to address this issue, developing some moving boundary heat exchanger models. Jiang et al. [32] proposed an iterative segment subdivision approach to model a fin-tube heat exchanger. This approach was then adopted and investigated in microchannel heat exchanger models by Singh et al. [61] and Huang et al. [62]. Joppolo et al. [7] used a segment insertion method, which is proposed by Iu et al. [60], to model a fin-and-tube condenser. This method calculates the approximate length from the inlet to the phase change point. Huang et al. [63] improved it and developed 'One-Segment Insertion' and 'Five-Segment Insertion' methods.

In the present study, based on the segment subdivision technique, an approach named 'Segment Self-Subdivision Method' is developed to track the phase change point. Compared with the conventional methods, this model introduces two sub-segment re-judgement links before and after the transition segment being divided into the initial sub-segments, which support the model to find the appropriate number 
of the sub-segments automatically.

Figure 6 illustrates the strategy of the segment self-subdivision approach at the segment-level. More details are also described below.

1. Use the outlet enthalpy, $h_{\mathrm{r}}(i, j, k+1)$, and the saturation enthalpy, $h_{\mathrm{s}}(i, j, k+1)$, corresponding to the outlet pressure, $P_{\mathrm{r}}(i, j, k+1)$, to identify whether a segment coded by $(i, j, k)$ is the transition segment;

2. The criteria equation is expressed as Eq. (16). When segment $(i, j, k)$ is determined as the transition segment and the calculated enthalpy residual is larger than an acceptable tolerance, the segment self-subdivision is triggered;

$$
\left|\frac{h_{\mathrm{S}}(i, j, k+1)-h_{\mathrm{r}}(i, j, k+1)}{h_{\mathrm{S}}(i, j, k+1)}\right|>\varepsilon ?
$$

3. Until the transition sub-segment matching the criteria is found, the number summator of sub-segments stops. The rest sub-segments behind the transition sub-segment enter the $\varepsilon-N T U$ heat transfer calculation module.

To exame the computational efficiency of the segment self-subdivision method, a serpentine air-to-refrigerant condenser with 10 micro-fin tubes is selected. The whole condenser can be treated as a segment that has only one phase change point from de-superheating to condensation. As depicted in Fig. 7, several jumps are observed when the number of the sub-segments increases. Each climbing within a jump is a relative movement of the phase change boundary in the transition sub-segment. A real moving boundary is the boundary of the transition sub-segment, which is caused by the segment size decrease as the number of the sub-segments increases. As the phase change boundary moves forward relatively to the back boundary of the transition sub-segment, the calculation error caused by the correlation misuse reduces. Until the phase change boundary almost overlaps the back boundary of the transition sub-segment, the capacity reaches the peak of the climb as shown in the picture. After 
the overlap, the phase change boundary exceeds the back boundary and turns to be the former part of the next sub-segment. Then a capacity fall emerges, and the other climb starts. The ranges of the climb and fall become smaller as the number of the sub-segments increases and the size of the transition sub-segment decreases. These tendencies and regularities depend on the algorithm itself rather than the specific geometries or conditions. Moreover, the graph illustrates that the peaks of all the jumps are almost the same. This means that the model can find the proper number of the divided transition segments after the first climb in general cases, improving computational efficiency.

Thus, the segment self-subdivision method can be implemented in various heat exchanger configurations and inlet conditions, neglecting whether the number and size of the sub-segments and the length of the iteration step are properly selected. This improves the accuracy and stability of the model and reduces the computational cost.

\subsection{Determination of mass flow rates in tubes for a flow pass}

As the red dash lines depicts in Fig. 8, a unique flow path starts at the tube-pass inlet and ends at the tube-pass outlet along any heat transfer tube in the tube-pass part. In the unique flow path, total pressure drop, $\Delta P(i, j)$, can be divided into three parts, the pressure drops in the inlet header part, $\Delta P_{\text {inh }}(i, j)$, in the heat transfer tube part, $\Delta P_{\mathrm{t}}(i, j)$, and in the outlet header part, $\Delta P_{\text {outh }}(i, j)$, as expressed in Eq. (17).

$$
\Delta P(i, j)=\Delta P_{\text {inh }}(i, j)+\Delta P_{\mathrm{t}}(i, j)+\Delta P_{\text {outh }}(i, j)
$$

The mass flow rate varies in the inlet and outlet headers as refrigerant streams are separated or mixed in the heat transfer tube, generating different local pressure losses in the headers. Based on fluid mechanics principles that the total pressure drop $(\Delta P(i, j))$ of any flow path in the tube-pass part is the same as the overall pressure drop 
shows.

$$
\Delta P(i, 1)=\cdots=\Delta P(i, 1)=\Delta P(i)
$$

The pressure drops in the inlet, $\Delta P_{\text {inh }}(i, j)$, or outlet headers, $\Delta P_{\text {outh }}(i, j)$, include

frictional pressure drop, $\Delta P_{\text {f,inh/outh }}(i, j)$, gravitational pressure drop, $\Delta P_{\mathrm{g}, \text { inh/outh }}(i, j)$, and

the local minor loss because of the tube protrusion, $\Delta P_{\mathrm{pt}, \text { inh/outh }}(i, j)$.

$$
\Delta P_{\text {inh } / \text { outh }}(i, j)=\Delta P_{\text {f,inh } / \text { outh }}(i, j)+\Delta P_{\text {g,inh } / \text { outh }}(i, j)++\Delta P_{\mathrm{pt}, \text { inh } / \text { outh }}(i, j)
$$

The gravitational component of a horizontal tube is zero. Thus the pressure drop, $\Delta P_{\mathrm{t}}(i, j)$, in the heat transfer tube contains the sum of all segment pressure drops, tube.

$$
\begin{gathered}
\Delta P_{\mathrm{t}(i, j)}=\Delta P_{\mathrm{c}}(i, j)+\sum_{K=1}^{\mathrm{NS}} \Delta P_{\mathrm{r}}(i, j, k)+\Delta P_{\mathrm{e}}(i, j) \\
\Delta P_{\mathrm{r}}(i, j, k)=\Delta P_{\mathrm{f}, \mathrm{r}}(i, j, k)+\Delta P_{\mathrm{m}, \mathrm{r}}(i, j, k)
\end{gathered}
$$

Sudden contraction/expansion local losses caused by the flow cross area changes occur when refrigerant flows between a tube and a header. The segment pressure drops, $\Delta P_{\mathrm{r}}(i, j, k)$, includes frictional, $\Delta P_{\mathrm{f}, \mathrm{r}}(i, j, k)$, and deceleration, $\Delta P_{\mathrm{m}, \mathrm{r}}(i, j, k)$, pressure drop components. All the correlations used in this part can be found in table 2 .

\subsection{Mass flow rate distribution calculation using genetic algorithm}

The earlier models of flow mal-distribution for air-to-refrigerant heat exchangers are summarized in table 1 . In most of these models algorithms are not provided to determine the flow distribution in order to balance the pressure drop among flow paths. For a conventional tube-fin heat exchanger, the refrigerant flow splits into 
several branches through a division tube bend, Liu et al. [64], Jiang et al. [32] and Jappolo et al. [7] applied Jung's correlation to calculate the refrigerant distribution readily. But for MPFCs with headers at the both ends of the tubes, the mass flow rate along a path varies because that the flow is divided inside the inlet header and merged inside the outlet header. This method is not valid. Wang et al. [10], Albanque et al. [33] implemented their algorithms and $\mathrm{Hu}$ et al. [65] introduced the Quasi-Newton method to MPFCs models. All these algorithms use an initial unified distribution, then define a searching direction to iterate until the convergence achieved. Similar to most of the conventional optimization and blind-search techniques, these algorithms only consider one single location at a time (Goldberry [66]) and are sensitive to the local minima (or maxima). The genetic algorithm, with only an objective function, is able to avoid part of this problem since there is no notion of direction in the search. The GA does not require derivative information or any complex method to find the next best move (Goldberry [66]). Many researchers applied the GA to design and optimize heat exchangers and obtained impressive achievements (Xie et al. [67], Amini et al. [68] and Wang et al. 2015 [69]). Therefore, the present model adopts the GA to calculate the refrigerant flow distribution.

In this model, the number of the variables depends on the number of the tubes (NT) in the current analyzed tube-pass part. The NT-dimensional array $(C(m, n))$ shown in Eq. (23) is encoded with the refrigerant flow distribution profile in nearby tube pass as a chromosome.

$$
C(m, n)=[G(i, 1), \ldots, G(i, j), \ldots, G(i, \mathrm{NT})](m, n)
$$

The constraint conditions to generate the initial population, $P(0)$ coded by the array $[C(0,1), \ldots, C(0, n), \ldots C(0, \mathrm{PN})]$, are defined as follows: 


$$
\left\{\begin{array}{c}
0<G(i, 1)<G(i) \\
G(i, 1)+\cdots+G(i, j)+\cdots G(i, \mathrm{NT})=G(i)
\end{array}\right.
$$

Two sets of specific codes are used, $i, j$ and $m, n . i, j$ keep the same meaning that

mentioned above. $m, n$ represent the genetic code, describing the NO. $n$ chromosome in the $m$ th generation population. The $P$ means population. The $\mathrm{PN}$ is the population size. 0 represents the initial generation and the $G(i)$ is the total refrigerant mass flux entering the current analysed tube pass.

The standard deviation (SD) is adopted as the single objective function (fitness function) to quantify the dispersion of a set of flow path pressure drops $([\Delta P(i, 1), \ldots$, $\Delta P(i, j), \ldots, \Delta P(i, \mathrm{NT})](m, n))$, which is calculated by Eq. (24). To minimise the SD value, all flow paths in the current tube-pass part have the same pressure drop stipulation to match.

$$
\begin{gathered}
\mathrm{SD}=\sqrt{\frac{\sum_{j=1}^{\mathrm{NT}}(\Delta P(i, j)-\Delta \bar{P}(i))^{2}}{\mathrm{NT}-1}} \\
\Delta \bar{P}(i)=\frac{1}{\mathrm{NT}} \sum_{j=1}^{\mathrm{NT}} \Delta P(i, j)
\end{gathered}
$$

The selection operator uses the 'Deterministic Sampling' method (Yao et al. [70]) to pick the individuals with better values of fitness function from the current population and insert their duplication into the mating pool. A fitter chromosome is more likely to be selected. A simple arithmetic crossover named Haupt's method (Haupt et al. [71]) is employed as the crossover operator to generate new chromosomes by combining the two parents selected from the mating pool. The equations are presented as follows:

$$
\left\{\begin{array}{l}
C_{1}=a f_{1}+(1-a) f_{2} \\
C_{2}=a f_{2}+(1-a) f_{1}
\end{array}\right.
$$

$C_{1}$ and $C_{2}$ are the offspring. $f_{1}$ and $f_{2}$ are the parents. $\alpha$ represents a random float value 
between 0 and 1 .

The mutation operator maintains the population diversity to prevent the program from converging at a local solution, with the limitation of the algorithm converge speed. To accelerate the algorithm converge speed, an elite-preservation strategy proposed by Varadharajan and Rajendran [72] is employed, protecting the "elites"- the highly-fitted individuals from crossover and mutation. The flow chart of this procedure is shown in Fig. 9.

To check the convergence stability, the GA is applied to calculate the refrigerant flow distribution profile in the first tube pass (containing five heat transfer tubes) of the test condenser in the given inlet conditions. As listed in table 4, five repetition calculations are carried out, where the population size and the stop generation number are 1000 and 50, respectively. When the algorithm stops at the SGN, the chromosome with the lowest SD value from the last generation is recorded as the solution to the original problem. The corresponding pressure drop of each flow path in the current tube pass is almost the same. As shown in the table below, the chromosome of the refrigerant flow distribution profile $\left([G(1), \ldots, G(i), \ldots, G(\mathrm{NT})]\right.$, unit: $\mathrm{kg} / \mathrm{m}^{2}$ s) makes perfect convergence at the same position every time, suggesting the good stability of the GA in the present work.

The GA of the present work shows good convergence ability. Like the ongoing evolving process, the selection operator of the GA washes the individuals with worse fitness out, as the individuals with better fitness have higher probabilities to survive to the next generation. The crossover operator of the GA select fitter individuals as the parents to create part of the next generation. As shown in Fig.10, each large colour block represents population of 1000 individuals of one generation. The small squares in different colours indicate the individuals with different SD values, of which darker 
colour means smaller SD value of the individuals. Apparently, generation after generation, the percentage of the elites in population grows larger and larger. Figure 11 displays the variation of the SD value with the generation number. The value in this figure adopts the smallest SD value of the population. After the fifteenth or sixteenth generation, the smallest SD value drops below 1.0 rapidly. In most instances, the dispersion degree of the pressure drops of the flow paths in the current analyzed tube-pass part meets the requirement. So criteria is introduced to reduce the iteration cost in the future work.

After assessing the algorithm's performance in a few trial runs, the configurations of the GA are adjusted, as outlined in table 3.

\subsection{Overall calculation scheme of the MPFCs-LS model}

Based on the discussion above, a 2D-strategy with three-level division of the condenser, a segment heat transfer calculation with the $\varepsilon-N T U$ method in section 2.1 , a phase change boundary tracking method named 'segment self-subdivision' in section 2.2, and a prediction approach of the refrigerant flow distribution combining the pressure balance principle in section 2.3, and an optimal searching algorithm, GA, in section 2.4 are proposed. All the modules implemented constitute the solution method of the liquid-vapor separation condenser, as depicted in Fig. 12.

The program codes mentioned above including the genetic algorithm are written by the authors in FORTRAN language. Subroutines contained in REFPROP 9.0, re called in the simulation process to calculate the thermodynamic properties and transport properties of the fluids. 


\section{Experimental}

\subsection{Test condenser}

The condenser tested in this study is shown in Fig. 13. This heat exchanger adopts the optimal tube-pass arrangement of $5 \rightarrow 3 \rightarrow 2 \rightarrow 1 \rightarrow 1 \rightarrow 1 \rightarrow 1$ according to the previous study of the author (Hua et al. [1]). As shown in Fig. 13, two headers are assembled at both ends of a heat transfer tube, and five baffles are inserted in the headers. In general, if baffles with orifices are used as liquid-vapor separators in MPFC-LS, because of the superheat or high quality condition of the inlet fluid, it is impossible or difficult to form liquid films on the baffles. Therefore, the first baffle is set as a shelf to prevent vapor from skipping the current tube pass and flowing into the next tube pass directly. The rest four baffles are liquid-vapor separators with specific designs. The structure of the baffles used in the test condenser in the present work was selected from 50 designs in a series of experiments using the same condensers. The geometries of the liquid-vapor separators can be found in Zhong et al. [22] and Chen et al. [73]. The geometry and dimensions of the MPFC-LS are given in tables 5-7.

\subsection{Apparatus}

The schematic of the apparatus is shown in Fig. 14. A vapor compression refrigeration system including the air loop, refrigerant loop and four water loops is installed separately inside a climate-control chamber. An air-handling unit, consisting of a refrigeration unit, an electrical heater, a humidifier, and a fan, maintains the chamber at the required temperature and humidity.

The air loop is an insulated open wind tunnel placed in the environmental chamber. A variable speed fan at the tunnel terminal exhausts the air flow across the condenser and then through the whole tunnel. Ahead of and behind the condenser, 
there are two air sampling units to measure the dry and wet bulb temperatures of the air flow at the inlet and outlet of the heat exchanger. A set of standard flow nozzles and micro differential pressure transmitter are mounted in the posterior tunnel to measure the air flow rate.

The refrigerant loop is composed of four main components, electronic expansion valve, compressor, evaporator, and the tested condenser. The electronic expansion valve is used to control the super-heat degree of the evaporator. An external frequency inverter controls the speed of the AC compressor motor to adjust the circulated refrigerant flow rate. An auxiliary condenser is settled in a branch behind the compressor to regulate the operating pressure for the condenser. Ahead of the tested MPFC-LS, a pre-cooler is used to cool and condense the superheated refrigerant from the compressor to achieve the given inlet condition of the MPFC-LS. Four water loops consist of the evaporator, auxiliary condenser, the pre-cooler, and the sub-cooler.

$\mathrm{R} 134 \mathrm{a}$ is chosen as the refrigerant in this study. Pt 100 platinum resistance thermometers are adopted to measure the refrigerant and water temperatures. Six absolute strain-gage pressure transducers, of which the calibration carried out before the experiments, are used to measure the refrigerant pressure. A Coriolis mass flow meter and magnetic flow meters are used to measure the refrigerant flow rate and water flow rate, respectively. A data logger and a computer are used to record the measurement data. Table 8 summaries the ranges and accuracies of the measured quantities.

\subsection{Data reduction and uncertainty analysis}

The refrigerant loop was evacuated for sufficiently longer time by vacuum pump 
before R134a was charged. Data are collected when the experimental system reaches

470

471 a steady state for at least 45 minutes for a set operating condition. This is evaluated by the energy balance between the refrigerant and air sides within 5\%, given by Eq. (27):

$$
\left|\frac{2\left(Q_{\mathrm{r}}-Q_{\mathrm{a}}\right)}{Q_{\mathrm{r}}+Q_{\mathrm{a}}}\right| \leq 5 \%
$$

The heat transfer rates at the refrigerant and air sides are calculated by the mass flow rates and the enthalpy difference between the inlet and outlet of the condenser.

$$
\begin{aligned}
& Q_{\mathrm{a}}=\dot{m}_{\mathrm{a}}\left(h_{\mathrm{a}, \text { out }}-h_{\mathrm{a}, \text { in }}\right) \\
& Q_{\mathrm{r}}=\dot{m}_{\mathrm{r}}\left(h_{\mathrm{r}, \text { in }}-h_{\mathrm{r}, \text { out }}\right)
\end{aligned}
$$

In the present experiment, the refrigerant at the inlet of the test condenser appears two-phase flow, as shown in Fig. 14. The enthalpy at the inlet of the condenser, $h_{\mathrm{r} \text {,in }}$, is taken to be the enthalpy, $h_{\mathrm{r}, \mathrm{pc} \text {,out, }}$ at the exit of the pre-cooler. Since the refrigerant at the exit of the compressor i.e. the inlet of the pre-cooler is at superheated state, the enthalpy $h_{\mathrm{r}, \mathrm{pc} \text {,in }}$ is obtained by measured pressure and temperature and hence the enthalpy, $h_{\mathrm{r}, \text { in }}$, is calculated by Eqs. (30) and (31).

$$
\begin{gathered}
Q_{\mathrm{pc}}=\dot{m}_{\mathrm{c}, \mathrm{pc}} \cdot c_{\mathrm{p}, \mathrm{wat}}\left(T_{\mathrm{c}, \mathrm{pc}, \mathrm{out}}-T_{\mathrm{c}, \mathrm{pc}, \mathrm{in}}\right) \\
h_{\mathrm{r}, \mathrm{in}}=h_{\mathrm{r}, \mathrm{pc}, \mathrm{out}}=h_{\mathrm{r}, \mathrm{pc}, \mathrm{in}}-\frac{Q_{\mathrm{pc}}}{\dot{m}_{\mathrm{r}}}
\end{gathered}
$$

The uncertainty of heat transfer rate is estimated to be within $\pm 2.52 \%$ by Eq. (32) (Taylor and Kuyatt [74]), and it of pressure drop is within $\pm 2.15 \mathrm{kPa}$.

$$
\frac{\delta Q}{Q}=\left\{\sum_{i=1}^{N}\left(\frac{\partial Q}{\partial X_{i}} \delta X_{i}\right)^{2}\right\}^{\frac{1}{2}}
$$

The $X_{i}$ represents independent quantities measured.

All the thermodynamic and transport properties of the fluids in the present work are calculated by REFPROP 9.0 [75]. 


\section{Validation of the model}

The experiments were conducted under the fixed conditions of inlet pressure 1160 $\mathrm{kPa}$ (saturation temperature of $45^{\circ} \mathrm{C}$ ) and refrigerant mass flux $533 \mathrm{~kg} / \mathrm{m}^{2} \mathrm{~s}$ and the data cover $\chi_{\text {ave }}$ in the ranges of $0.30 \sim 0.66$ and $0.27 \sim 0.72$, respectively, corresponding to heat transfer capacities of $1525 \mathrm{~W}$ and $1125 \mathrm{~W}$. The value $\chi_{\text {ave }}$ represents the average value of the vapor qualities at the inlet and outlet of the test condenser, which is defined by Eq. (33)

$$
\chi_{\mathrm{ave}}=\frac{\left(\chi_{\mathrm{in}}-\chi_{\mathrm{out}}\right)}{2}
$$

The ratios of predicted and measured heat transfer rates, $Q_{\text {pre }} / Q_{\text {exp }}$, are plotted as functions of $\chi_{\text {ave }}$ in Fig. 15. Two correlations (Yu and Koyama [48] and Cavallini et al. [44]) are used to calculate heat transfer during R134a condensation in the annual flow regime in horizontal micro-fin tubes. As is seen from Fig. 15, 72\% of predicted heat transfer capacities are within $\pm 20 \%$ and almost all the predicted values are within $\pm 30 \%$, compared with the experimental values.

The ratios of predicted and measured pressure drops, $\Delta P_{\text {pre }} / \Delta P_{\text {exp }}$, are plotted as functions of $\chi_{\text {ave }}$ in Fig. 16. Three correlations are used to calculate the frictional pressure drop during R134a condensation in horizontal micro-fin tubes. As is seen from Fig. 16, in general the predictions of the pressure drops by the correlation of Haraguchi et al. [49] appears better than those of the correlations of Goto et al. [50] and Nozu et al. [51] throughout the whole range of vapor quality. In the lower vapor quality range of 0.25 to 0.35 , all the three correlations underpredict the pressure drop to $-48.9 \%$. About $57 \%$ of the predictions are within $\pm 20 \%$ and $80 \%$ of the predictions are $\pm 30 \%$.

The performance of each correlation is also assessed quantitatively in terms of the 
arithmetic mean deviation of relative residuals (a.m.) and the root-mean-square deviation of relative residuals (r.m.s), which are defined as follows:

$$
\begin{gathered}
\text { a.m. }=\frac{1}{N} \sum \frac{X_{\text {exp }}-X_{\text {pre }}}{X_{\exp }} \times 100 \% \\
\text { r.m.s. }=\sqrt{\frac{1}{N} \sum\left(\frac{X_{\exp }-X_{\text {pre }}}{X_{\exp }}\right)^{2}} \times 100 \%
\end{gathered}
$$

Tables 9 and 10 give the comparison results for two heat transfer capacities of the test condenser. The r.m.s values of Yu and Koyama [48] and Cavallini et al. [44] correlations are $12.6 \%$ and $7.5 \%$, respectively. The r.m.s values of Haraguchi et al. [49], Nozu et al. [50] and Goto et al. [51] correlations are 20.6\%, 28.2\% and 26.7\%, respectively.

\section{Conclusions}

A distributed parameter model and numerical methods have been developed to simulate the heat transfer performance of MPFCs-LS. The $\varepsilon-N T U$, a free-iteration method, was used to calculate the heat transfer between the refrigerant and air sides. The locations of onset and completion of condensation in the refrigerant flow side were correctly traced and the flow mal-distribution in the refrigerant side was determined by genetic algorithm. The flow patterns of condensation were identified to use relevant correlations for heat transfer and pressure drop. The predictions of the model agreed well with the experimental data with the root-mean-square deviations of heat transfer capacity and pressure drop being within $7.5 \%$ and $20.6 \%$, respectively.

The model and numerical methods provide a useful tool for design and performance simulation and optimization of these new advanced condensers. 
531 The authors gratefully acknowledge the financial supports from the Engineering

532 and Physical Sciences Research Council (EPSRC) of the UK (EP/N020472/1), the

533 Royal Society of IEC \NSFC \170543-International Exchanges 2017 Cost Share (China)

534 and the National Natural Science Foundation (NSFC) of China (51736005).

535

536 Nomenclature

$537 \quad A \quad$ area

$538 \quad c \quad$ specific heat capacity

$539 \quad C \quad$ chromosome

$540 \quad c_{p} \quad$ isobaric specific heat capacity

$541 d_{\mathrm{i}} \quad$ fin tip diameter of the tube

$542 \quad D_{0} \quad$ outside tube diameter

$543 f \quad$ parent

$544 \mathrm{~g} \quad$ specific force of gravity

$545 \quad G \quad$ mass flux

$546 \quad h \quad$ specific enthalpy

$547 \quad h_{\mathrm{f}} \quad$ fin height

$548 \quad i \quad$ tube pass index

$549 j \quad$ flow path index

$550 k \quad$ tube cell index

$551 \quad L \quad$ tube length

$552 m$ mass flow rate, population index

$553 \quad N_{\mathrm{f}} \quad$ number of the louvre fins along a tube

$554 n \quad$ chromosome index 


\begin{tabular}{|c|c|c|}
\hline 555 & $N_{\mathrm{p}}$ & number of tube pass \\
\hline 556 & $N_{\mathrm{s}}$ & number of segment \\
\hline 557 & $N_{\mathrm{mf}}$ & number of microfin \\
\hline 558 & $N_{\mathrm{t}}$ & number of tube \\
\hline 559 & $N_{\mathrm{tp}}$ & number of tube per pass \\
\hline 560 & $N_{\text {tr }}$ & number of longitudinal tube row \\
\hline 561 & $N T U$ & number of transfer unit \\
\hline 562 & $P$ & pressure, population \\
\hline 563 & $P_{1}$ & longitudinal tube pitch \\
\hline 564 & $P_{\mathrm{n}}$ & population size \\
\hline 565 & $P_{\mathrm{f}}$ & fin pitch \\
\hline 566 & $P_{\mathrm{t}}$ & transverse tube pitch \\
\hline 567 & $P F$ & penalty factor \\
\hline 568 & $Q$ & heat transfer rate \\
\hline 569 & $S_{\mathrm{f}}$ & fin space \\
\hline 570 & $S_{\mathrm{h}}$ & height of a slit \\
\hline 571 & $S_{\mathrm{n}}$ & number of slit in an enhanced zone \\
\hline 572 & $S_{\mathrm{s}}$ & breadth of a slit in the direction of air flow \\
\hline 573 & $T$ & temperature \\
\hline 574 & $t_{\mathrm{b}}$ & fin width at fin root \\
\hline 575 & $U$ & overall heat-transfer coefficient \\
\hline \multicolumn{3}{|l|}{576} \\
\hline 577 & Acronyms & \\
\hline 578 & a.m. & arithmetic-mean deviation \\
\hline 579 & AMTD & arithmetic temperature difference \\
\hline
\end{tabular}


580 GA genetic algorithm

581 HX heat exchanger

582 LMTD logarithmic mean temperature difference

583 LS liquid-vapor separation

584 MPFC multi-pass parallel flow condenser

585 PFMC parallel flow microchannel condenser

586 PFME parallel flow microchannel evapourator

587 PFMHX parallel flow microchannel heat exchanger

588 r.m.s. root-mean-square deviation

589 RFMD refrigerant flow mal-distribution

590 SD standard deviation

591 SGN stop generation number

592 NT number of tube

593

594 Greek symbols

$595 \quad \beta \quad$ spiral/helix angle

$596 \gamma \quad$ apex angle

$597 \varepsilon \quad$ void fraction, effectiveness, residual

$598 \chi \quad$ mass quality

$599 \quad \delta_{\mathrm{f}} \quad$ fin thickness

600

601 Subscripts

602 a air side

603 ave average

604 c contraction, coolant 


\begin{tabular}{|c|c|c|}
\hline 605 & $\mathrm{e}$ & expansion \\
\hline 606 & $\exp$ & experimental \\
\hline 607 & $\mathrm{f}$ & frictional \\
\hline 608 & g & gravitational \\
\hline 609 & $i$ & independent measurement index \\
\hline 610 & in & inlet \\
\hline 611 & inh & inlet header \\
\hline 612 & $\mathrm{~m}$ & momentum \\
\hline 613 & $\max$ & maximum \\
\hline 614 & $\min$ & minimum \\
\hline 615 & $\operatorname{mix}$ & mixed \\
\hline 616 & out & outlet \\
\hline 617 & outh & outlet header \\
\hline 618 & $\mathrm{pc}$ & pre-cooler \\
\hline 619 & pre & predicted \\
\hline 620 & $\mathrm{pt}$ & protrusion \\
\hline 621 & $\mathrm{r}$ & refrigerant \\
\hline 622 & $\mathrm{~s}$ & saturation \\
\hline 623 & $\mathrm{t}$ & tube \\
\hline 624 & $\mathrm{~W}$ & tube wall \\
\hline 625 & unmix & unmixed \\
\hline
\end{tabular}

\section{References}

628 1. Hua N, Chen Y, Chen E, Deng L, Zheng W, Yang Z. Prediction and verification of 629 the thermodynamic performance of vapour-liquid separation condenser. Energy, 
631

632

2. Ren T, Ding G, Wang T, Hu H. A general three-dimensional simulation approach for micro-channel heat exchanger based on graph theory. Applied Thermal Engineering, 2013, 59(1-2): 660-674.

3. Huang L, Lee MS, Saleh K, Aute V, Radermacher R. A computational fluid dynamics and effectiveness-NTU based co-simulation approach for flow mal-distribution analysis in microchannel heat exchanger headers. Applied Thermal Engineering, 2014, 65(1-2): 447-457.

4. Huang L, Aute V, Radermacher R. A model for air-to-refrigerant microchannel condensers with variable tube and fin geometries. International Journal of Refrigeration, 2014, 40: 269-281.

5. Zou Y, Tuo H, Hrnjak PS. Modeling refrigerant maldistribution in microchannel heat exchangers with vertical headers based on experimentally developed distribution results. Applied Thermal Engineering, 2014, 64(1-2): 172-181.

6. Hassan AH, Martinez-Ballester S, Gonzálvez-Maciá J. A comparative study between a two-dimensional numerical minichannel evaporator model and a classical effectiveness-NTU approach under different dehumidifying conditions. Science and Technology for the Built Environment, 2015, 21(5): 681-692.

7. Joppolo CM, Molinaroli L, Pasini A. Numerical analysis of the influence of circuit arrangement on a fin-and-tube condenser performance. Case Studies in Thermal Engineering, 2015, 6: 136-146.

8. Li H, Hrnjak P. Quantification of liquid refrigerant distribution in parallel flow microchannel heat exchanger using infrared thermography. Applied Thermal Engineering, 2015, 78: 410-418.

9. Liang YY, Liu CC, Li CZ, Chen JP. Experimental and simulation study on the air 
side thermal hydraulic performance of automotive heat exchangers. Applied Thermal Engineering, 2015, 87: 305-315.

657

658

659

660

661

662

663

664

665

666

667

668

669

670

671

672

673

10. Wang T, Gu B, Wu B, Ma H, Qian C. Modeling for multi-pass parallel flow condenser with the effect of refrigerant mal-distribution. International Journal of Refrigeration, 2015, 60: 234-246.

11. Yin XW, Wang W, Patnaik V, Zhou JS, Huang XC. Evaluation of microchannel condenser characteristics by numerical simulation. International Journal of Refrigeration, 2015, 54: 126-141.

12. Datta SP, Das PK, Mukhopadhyay S. Performance of a condenser of an automotive air conditioner with maldistribution of inlet air-Simulation studies and its experimental validation. International Journal of Heat and Mass Transfer, 2016, 98: 367-379.

13. Shojaeefard MH, Zare J. Modeling and combined application of the modified NSGA-II and TOPSIS to optimize a refrigerant-to-air multi-pass louvered fin-and-flat tube condenser. Applied Thermal Engineering, 2016, 103: 212-225.

14. Tian Z, Ma L, Gu B, Yang L, Liu F. Numerical model of a parallel flow minichannel evapourator with new flow boiling heat transfer correlation. International Journal of Refrigeration, 2016, 63: 1-13.

15. Zou Y, Li H, Tang K, Hrnjak P. Round-tube and microchannel heat exchanger modelling at wet air condition. Proceedings of 16th International Refrigeration and Air Conditioning Conference at Purdue; 2016 July 11-14; West Lafayette, United States. Purdue University: RayW. Herrick Laboratories; 2016, Paper 1774.

16. Li Z, Ling J, Aute V, Radermacher R. Investigation of port level refrigerant flow maldistribution in microchannel heat exchanger. Proceedings of 12th IEA Heat Pump Conference at Rotterdam; 2017 May 15-18; the Netherlands. 
17. Shojaeefard MH, Nourbakhsh SD, Zare J. An investigation of the effects of geometry design on refrigerant flow mal-distribution in parallel flow condenser using a hybrid method of finite element approach and CFD simulation. Applied Thermal Engineering, 2017, 112: 431-449.

18. Shojaeefard MH, Zare J, Nourbakhsh SD. Developing a hybrid procedure of one dimensional finite element method and CFD simulation for modeling refrigerant flow mal-distribution in parallel flow condenser. International Journal of Refrigeration, 2017, 73: 39-53.

19. Wu D, Wang Z, Lu G, Peng X. High-performance air cooling condenser with liquid-vapor separation. Heat Transfer Engineering, 2010, 31(12): 973-980.

20. Chen Y, Hua N, Deng L S. Performances of a split-type air conditioner employing a condenser with liquid-vapor separation baffles. International journal of refrigeration, 2012, 35(2): 278-289.

21. Chen Y, Hua N, Wu D. A comparative study of fin-and-tube heat exchangers with and without liquid-vapor separation in air conditioning units. International journal of green energy, 2014, 11(5): 488-499.

22. Zhong T, Chen Y, Hua N, Zheng W, Luo X, Mo S. In-tube performance evaluation of an air-cooled condenser with liquid-vapour separator. Applied Energy, 2014, 136: 968-978.

23. Zhong T, Chen Y, Zheng W, Hua N, Luo X. Experimental investigation on microchannel condensers with and without liquid-vapour separation headers. Applied Thermal Engineering, 2014, 73(2): 1510-1518.

24. Zhong T, Chen Y, Yang Q, Mo S, Luo X, Xu J. Experimental investigation on the thermodynamic performance of double-row liquid-vapour separation microchannel condenser. International Journal of Refrigeration, 2016, 67: 
25. Zhong T, Ding L, Chen S, Chen Y, Yang Q, Luo Y. Effect of a double-row liquid-vapor separation condenser on an air-conditioning unit performance. Applied Thermal Engineering, 2018, 142: 476-482.

26. Luo X, Xu J, Chen Y, Mo S. Mathematical optimization of the liquid separation condenser used in the organic Rankine cycle. Energy Procedia, 2015, 75: 3127-3132.

27. Luo X, Yi Z, Zhang B, Mo S, Wang C, Song M, Chen Y. Mathematical modelling and optimization of the liquid separation condenser used in organic Rankine cycle. Applied Energy, 2017, 185: 1309-1323.

28. Zou Y, Tuo H, Hrnjak PS. Two-phase refrigerant maldistribution in the vertical header and its effect on the heat exchanger performance as evapourator in heat pump mode. ASME 2012 International Mechanical Engineering Congress and Exposition. American Society of Mechanical Engineers; 2012, pp. 1823-1832.

29. Byun HW, Kim NH. An experimental study on refrigerant distribution in a two row/four pass parallel flow minichannel heat exchanger. Heat and Mass Transfer, 2016, 52(10): 2237-2255.

30. Domanski PA. EVAP-COND, simulation models for finned tube heat exchangers. National Institute of Standards and Technology Building and Fire Research Laboratory, Gaithersburg, MD, USA, 2003.

31. Jiang H, Aute V, Radermacher, R. A user-friendly simulation and optimization tool for design of coils. Proceedings of 9th International Refrigeration and Air Conditioning Conference at Purdue; West Lafayette, United States. Purdue University: RayW. Herrick Laboratories; 2002, Paper 546.

32. Jiang H, Aute V, Radermacher R. CoilDesigner: a general-purpose simulation and 
design tool for air-to-refrigerant heat exchangers. International Journal of Refrigeration, 2006, 29(4): 601-610.

33. Ablanque N, Oliet C, Rigola J, Perez-Segarra CD, Oliva A. Two-phase flow distribution in multiple parallel tubes. International Journal of Thermal Sciences, 2010, 49(6): 909-921.

34. Hwang ST, Soliman HM, Lahey RT, Phase separation in dividing two-phase flows, International Journal of Multiphase Flow, 1988, 14(4): 439-458.

35. Corberán JM, de Córdoba PF, Gonzálvez J, Alias F. Semiexplicit method for wall temperature linked equations (SEWTLE): a general finite-volume technique for the calculation of complex heat exchangers. Numerical Heat Transfer: Part B: Fundamentals, 2001, 40(1): 37-59.

36. Cavallini A, Brown JS, Del Col D, Zilio C. In-tube condensation performance of refrigerants considering penalization terms (exergy losses) for heat transfer and pressure drop. International Journal of Heat and Mass Transfer, 2010, 53(13-14): 2885-96.

37. Watanabe M, Katsuta M. A general prediction model of two-phase flow distribution in a multipass evapourator. Proceedings of 21 st International Congress of Refrigeration; Washington, D.C., USA; 2003, Paper ICR0378.

38. Byun HW, Kim NH. Two-phase refrigerant distribution in an intermediate header of a parallel flow minichannel heat exchanger. International Journal of Refrigeration, 2015, 59: 14-28.

39. Thome JR. On recent advances in modeling of two-phase flow and heat transfer. Keynote Address: 1st International Conference on Heat Transfer, Fluid Mechanics, and Thermodynamics (HEFAT 2002); 2002 April 8-10; Kruger Park, South Africa; 2002, 13 pages. 
40. Thome JR, Two-phase flow pattern map for evaporation in horizontal tubes. Proceedings of 1st International Conference on Heat Transfer, Fluid Mechanics, and Thermodynamics (HEFAT 2002); 2002 April 8-10; Kruger Park, South Africa; 2002, 7 pages.

41. Liebenberg L, Meyer JP. A review of flow pattern-based predictive correlations during refrigerant condensation in horizontally smooth and enhanced tubes. Heat Transfer Engineering, 2008, 29(1): 3-19.

42. Doretti L, Zilio C, Mancin S, Cavallini A. Condensation flow patterns inside plain and microfin tubes: A review. International Journal of Refrigeration, 2013, 36(2): 567-587.

43. Tandon TN, Varma HK, Gupta CP. A new flow regime map for condensation inside horizontal tubes. Journal of Heat Transfer, 1982, 104(4): 763-768.

44. Cavallini A, Del Col D, Mancin S, Rossetto L. Condensation of pure and near-azeotropic refrigerants in microfin tubes: A new computational procedure. International Journal of Refrigeration, 2009, 32(1): 162-174.

45. Kim NH. Condensation heat transfer and pressure drop of $\mathrm{R}-410 \mathrm{~A}$ in a $7.0 \mathrm{~mm}$ OD microfin tube at low mass fluxes. Heat and Mass Transfer, 2016, 52(12): 2833-2847.

46. Wang HS, Honda H. Condensation of refrigerants in horizontal microfin tubes: Comparison of prediction methods for heat transfer. International Journal of Refrigeration, 2003, 26:452-460.

47. Wang HS, Honda H. Condensation of refrigerants in horizontal microfin tubes: Comparison of prediction methods for heat transfer. International Journal of Refrigeration, 2003, 26:452-460.

48. Yu J, Koyama S. Condensation heat transfer of pure refrigerants in microfin tubes. 
In: Proc. Int. Refrigeration Conference at Purdue University, West Lafayette, USA, 1998. p. 325-30

782

49. Haraguchi H. Studies on condensation of HCFC-22, HFC-134a and HCFC-123 in horizontal tubes. Dr. Eng. thesis, Kyushu University, 1994 [in Japanese].

50. Nozu S, Katayama H, Nakata H, Honda H. Condensation of a refrigerant CFC11 in horizontal microfin tubes. Experimental Thermal and Fluid Science, 1998, 18:82-96.

51. Goto M, Inoue N, Ishiwatari N. Condensation and evaporation heat transfer of R410A inside internally grooved horizontal tubes. International Journal of Refrigeration, 2001, 24:628-38.

52. Wu Z, Sundén B, Wadekar V V, Li W. Heat transfer correlations for single-phase flow, condensation, and boiling in microfin tubes. Heat Transfer Engineering, 2015, 36(6): 582-595.

53. Friedel, L. Improved friction pressure drop correlation for horizontal and vertical two-phase pipe flow. European Two-phase Flow Group Meeting Paper E2, Ispra, Italy, 1979

54. Collier JG, Thome JR. Convective Boiling and Condensation. 3rd. New York: Oxford University Press; 1994.

55. Rouhani $\mathrm{Z}$ and Axelsson E, Calculation of volume void fraction in the subcooled and quality region. International Journal of Heat Mass Transfer, 1970, 285:77-86.

56. Thome JR. Engineering databook III, Wolverine Tube, Inc, Huntsville, AL, USA, 2004.

57. Shah RK, Sekulic DP. Fundamentals of heat exchanger design. John Wiley \& Sons, 2003.

58. Yin JM, Bullard CW, Hrnjak PS. Single-phase pressure drop measurements in a 
microchannel heat exchanger. Heat Transfer Engineering, 2002, 23(4): 3-12.

806

807

59. Wang CC, Lee WS, Sheu WJ. A comparative study of compact enhanced fin-and-tube heat exchangers. International Journal of Heat and Mass Transfer, 2001, 44(18): 3565-3573.

60. Iu I, Weber N A, Bansal P, Fisher DE. Applying the effectiveness-NTU method to elemental heat exchanger models. Ashrae Transactions, 2007, 113(1): 504-513.

61. Singh V, Aute V, Radermacher R. A heat exchanger model for air-to-refrigerant fin-and-tube heat exchanger with arbitrary fin sheet. International journal of refrigeration, 2009, 32(7): 1724-1735.

62. Huang L, Aute V, Radermacher R. 2012. A generalized effectiveness-NTU based variable geometry microchannel heat exchanger model. In: International Refrigeration and Air Conditioning Conference at Purdue. Purdue University, West Lafayette.

63. Huang L, Aute V, Radermacher R. A finite volume coaxial heat exchanger model with moving boundaries and modifications to correlations for two-phase flow in fluted annuli. International Journal of Refrigeration, 2014, 40: 11-23.

64. Liu J, Wei W J, Ding GL, Zhang CL, Fukaya M, Wang KJ and Inagaki T. A general steady state mathematical model for fin-and-tube heat exchanger based on graph theory. International Journal of Refrigeration, 2004, 27(8): 965-973.

65. Hu H, Zhang R, Zhuang D, Ding G, Wei W. Numerical model of two-phase refrigerant flow distribution in a plate evaporator with distributors. Applied Thermal Engineering, 2015, 75: 167-176.

66. Goldberg, DE. Genetic Algorithms in Search Optimization, and Machine Learning, Reading MA: Addison-Welsey, 1989.

67. Xie GN, Sundén B, Wang QW. Optimization of compact heat exchangers by a 
genetic algorithm. Applied Thermal Engineering, 2008, 28(8-9): 895-906.

831

68. Amini M, Bazargan M. Two objective optimization in shell-and-tube heat exchangers using genetic algorithm. Applied Thermal Engineering, 2014, 69(1):278-285.

69. Wang Z, Li Y, Zhao M. Experimental investigation on the thermal performance of multi-stream plate-fin heat exchanger based on genetic algorithm layer pattern design. International Journal of Heat and Mass Transfer, 2015, 82: 510-520.

70. Yao C, Chen HJ, Yu JB, Li JP. Application of Distributed Genetic Algorithm Based on Migration Strategy in Image Segmentation. Natural Computation. ICNC 2007: Third International Conference on Natural Computation; 2007 Aug 24-27; Haikou, China. 2002. p. 218-222.

71. Haupt, RL, Haupt, SE. Practical Genetic Algorithms (2nd ed.). 2004, Hobo-ken: Wiley.

72. Varadharajan TK, Rajendran C, A multi-objective simulated-annealing algorithm for scheduling in flow shops to minimize the makespan and total flow time of jobs, Eur. J. Oper. Res. 167 (2005) 772-795.

73. Chen X, Chen Y, Deng L, Mo S, Zhang H. Experimental verification of a condenser with liquid-vapor separation in an air conditioning system. Applied Thermal Engineering, 2013, 51(1-2): 48-54.

74. Taylor BN, Kuyatt CE. Guidelines for evaluating and expressing the uncertainty of NIST measurement results. Gaithersburg, MD, USA: National Institute of Standards and Technology, NIST TN 1297.

75. Lemmon EW, Huber ML, McLinden MO. NIST Standard Reference Database 23: Reference Fluid Thermodynamic and Transport Properties-REFPROP, Version 9.0. Standard Reference Data Program, National Institute of Standards and 
Technology, Gaithersburg, MD, 2010. 


\section{Figure Captions}

Fig. 1 Model of the condenser and numerical scheme

Fig. 2 Quantities at the inlets and outlets at both the refrigerant and air flow sides of a segment

Fig. 3 Simulation results plotted on the flow pattern map of Liebenberg and Meyer (2008)

Fig. 4 Simulation results plotted on the flow pattern map of Doretti et al. (2013)

Fig. 5 Flow chart of numerical simulation of segment using the $\varepsilon-N T U$ method

Fig. 6 Flow chart for determination of the locations of onset and completion of condensation

Fig. 7 Determination of the location of condensation onset

Fig. 8 Scheme of flow paths

Fig. 9 Flow chart of the genetic algorithm

Fig. 10 Population distributions progressing in generations of GA optimization

Fig. 11 Convergence of the optimized value with the number of generation

Fig. 12 Flow chart of the numerical simulation of MPFCs-LS

Fig. 13 Photograph of the MPFC-LS

Fig. 14 Schematic of the apparatus

Fig. 15 Comparison of predicted and measured heat transfer rates with vapour quality

Fig. 16 Comparison of predicted and measured pressure drops with vapor quality 


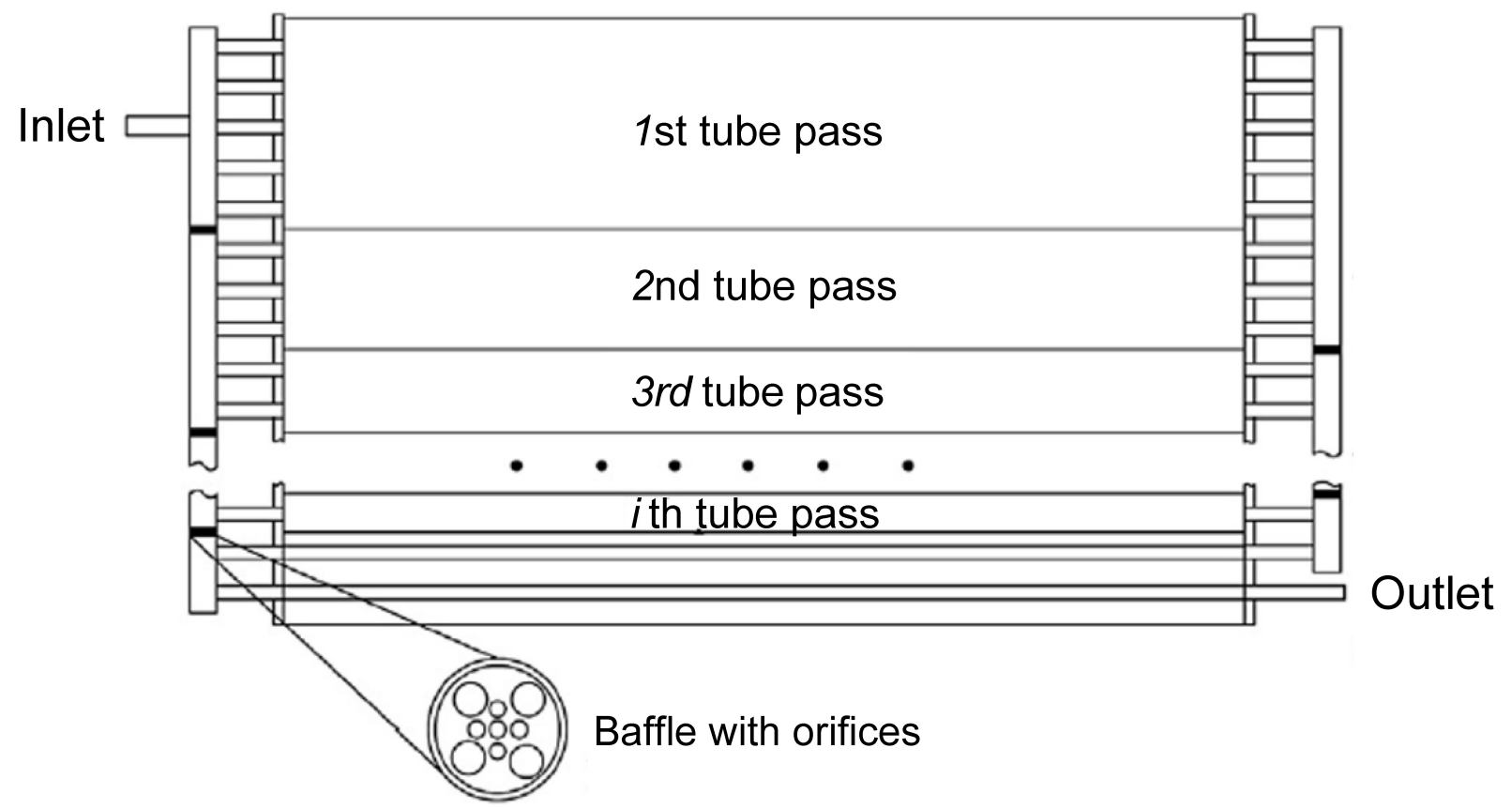

The Highest Level - 'Condenser Level'

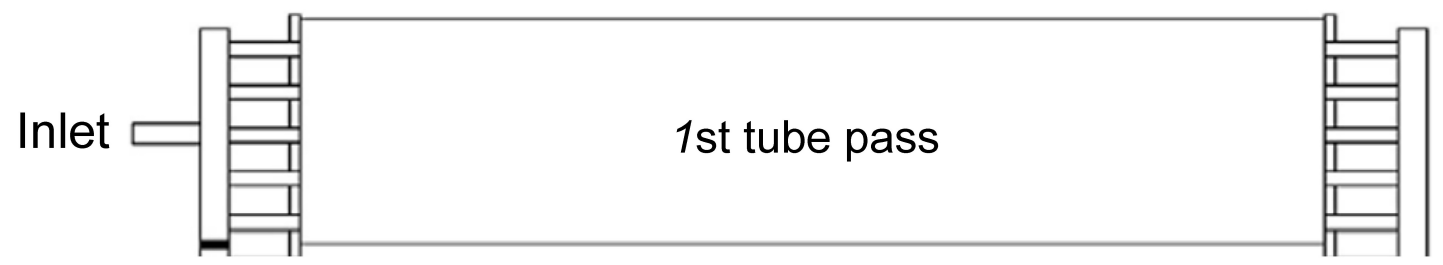

The Medium Level - 'Tube-pass Level'

Outlet

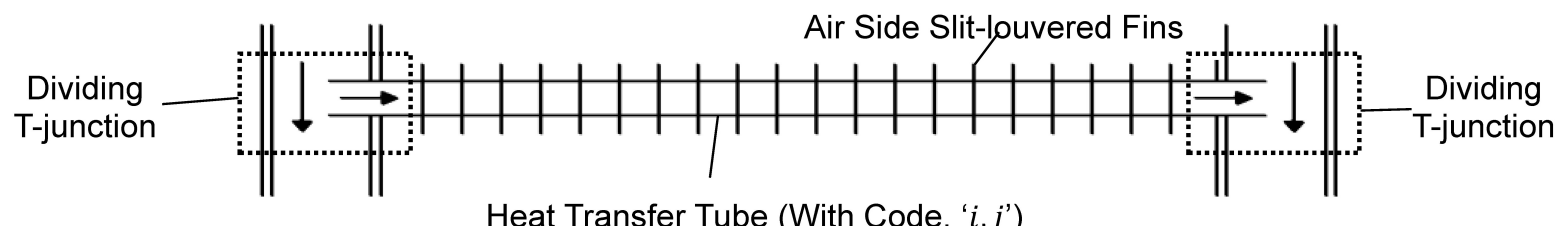

The Lowest Level - 'Branch Level' 


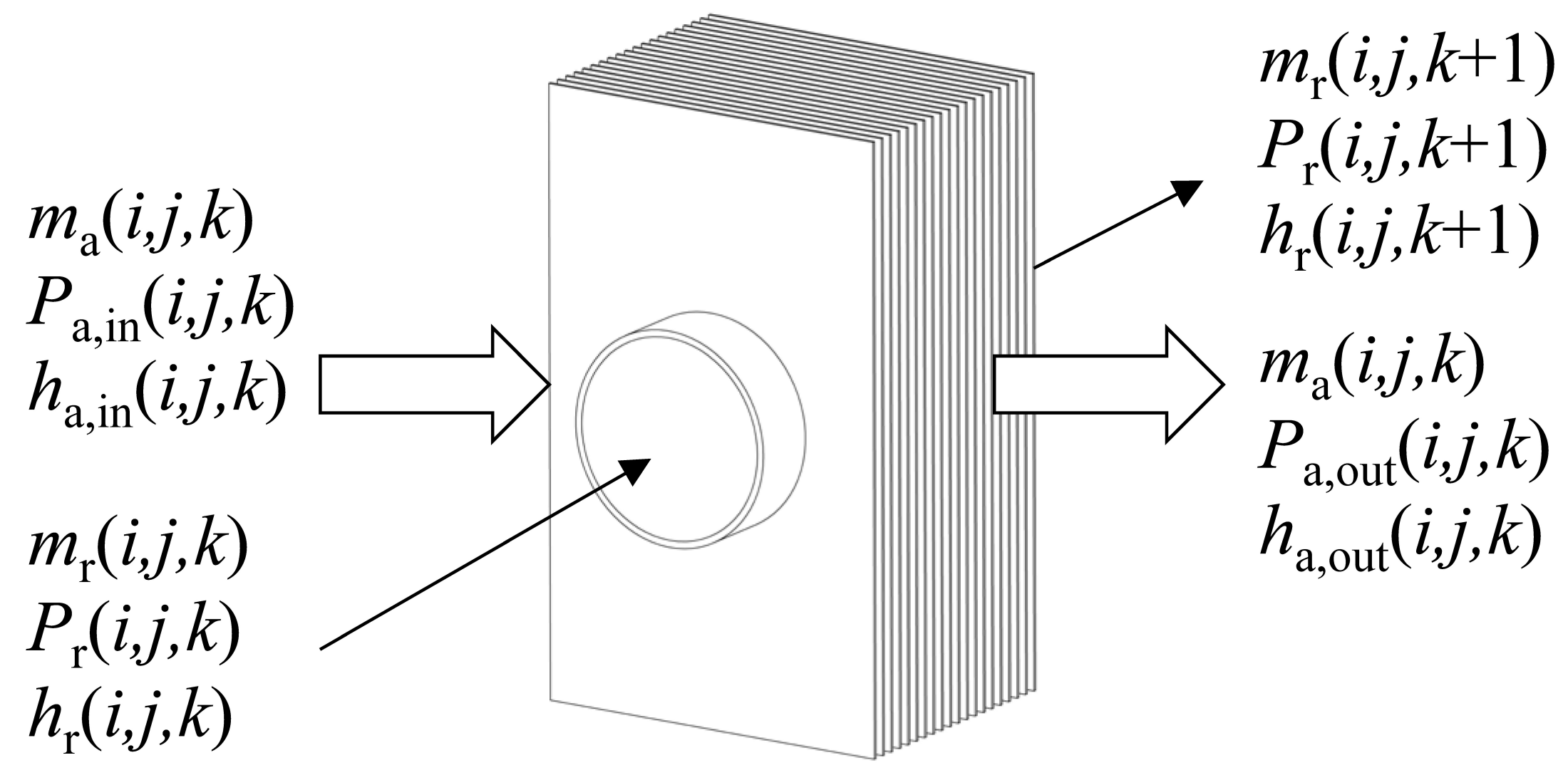




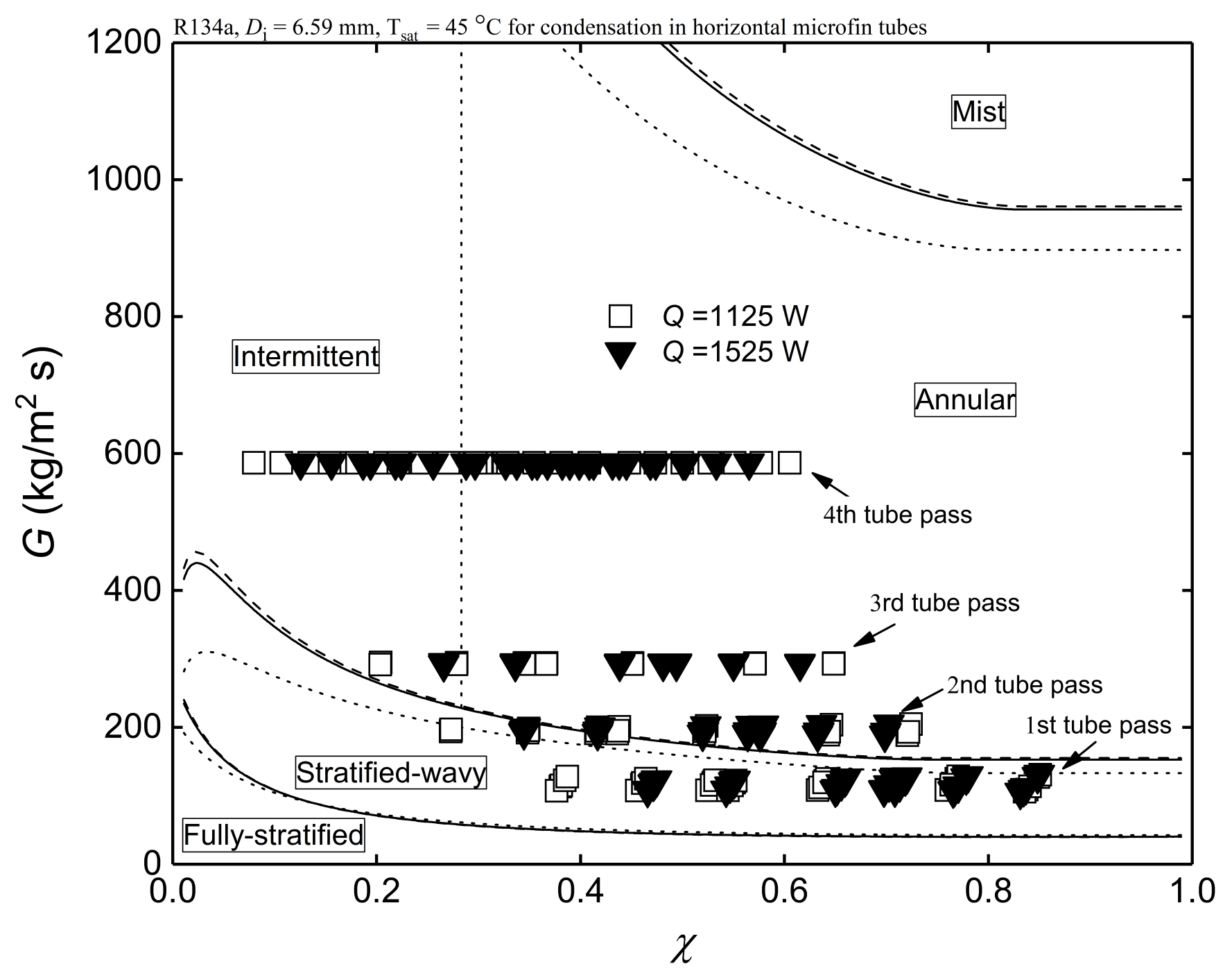




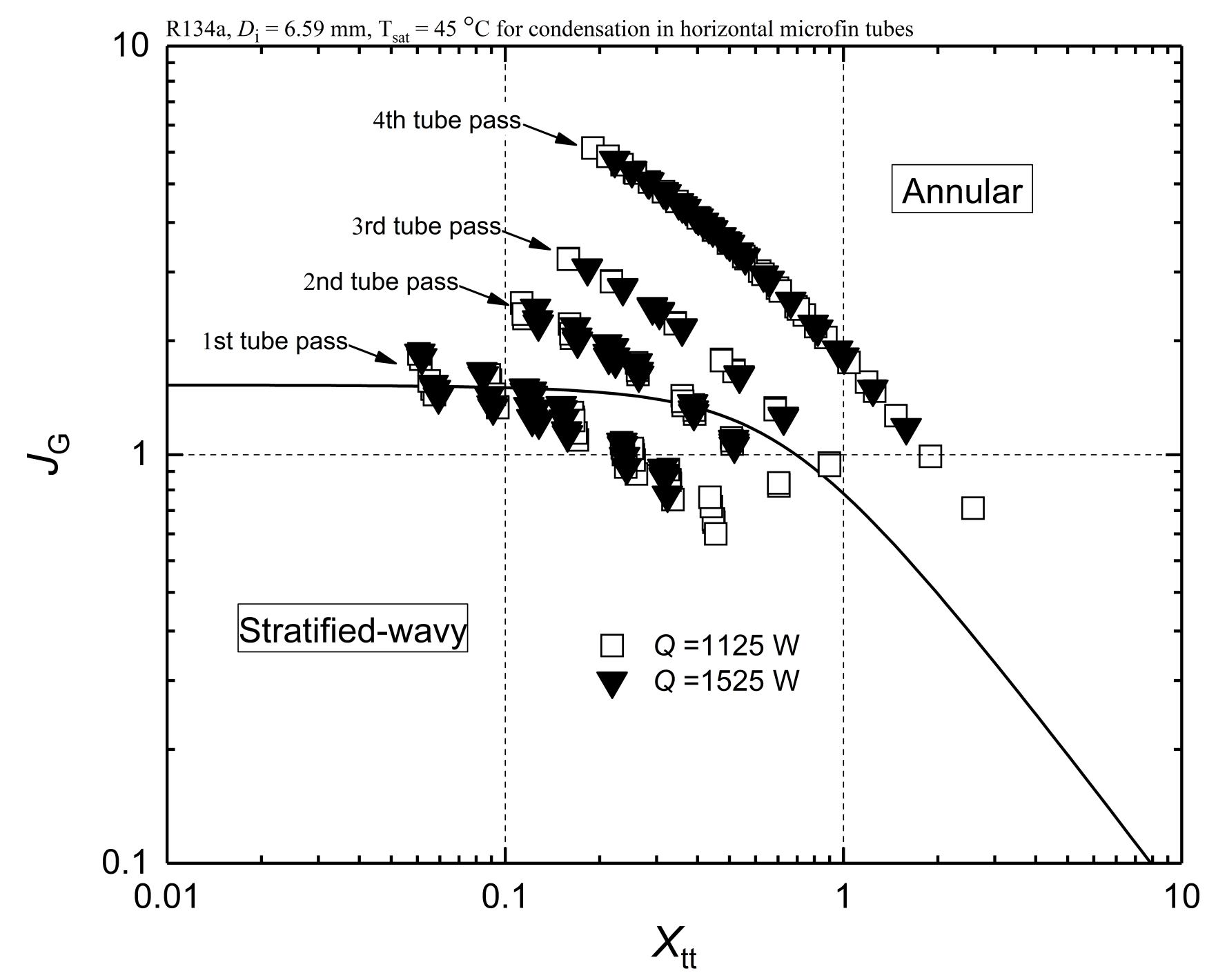




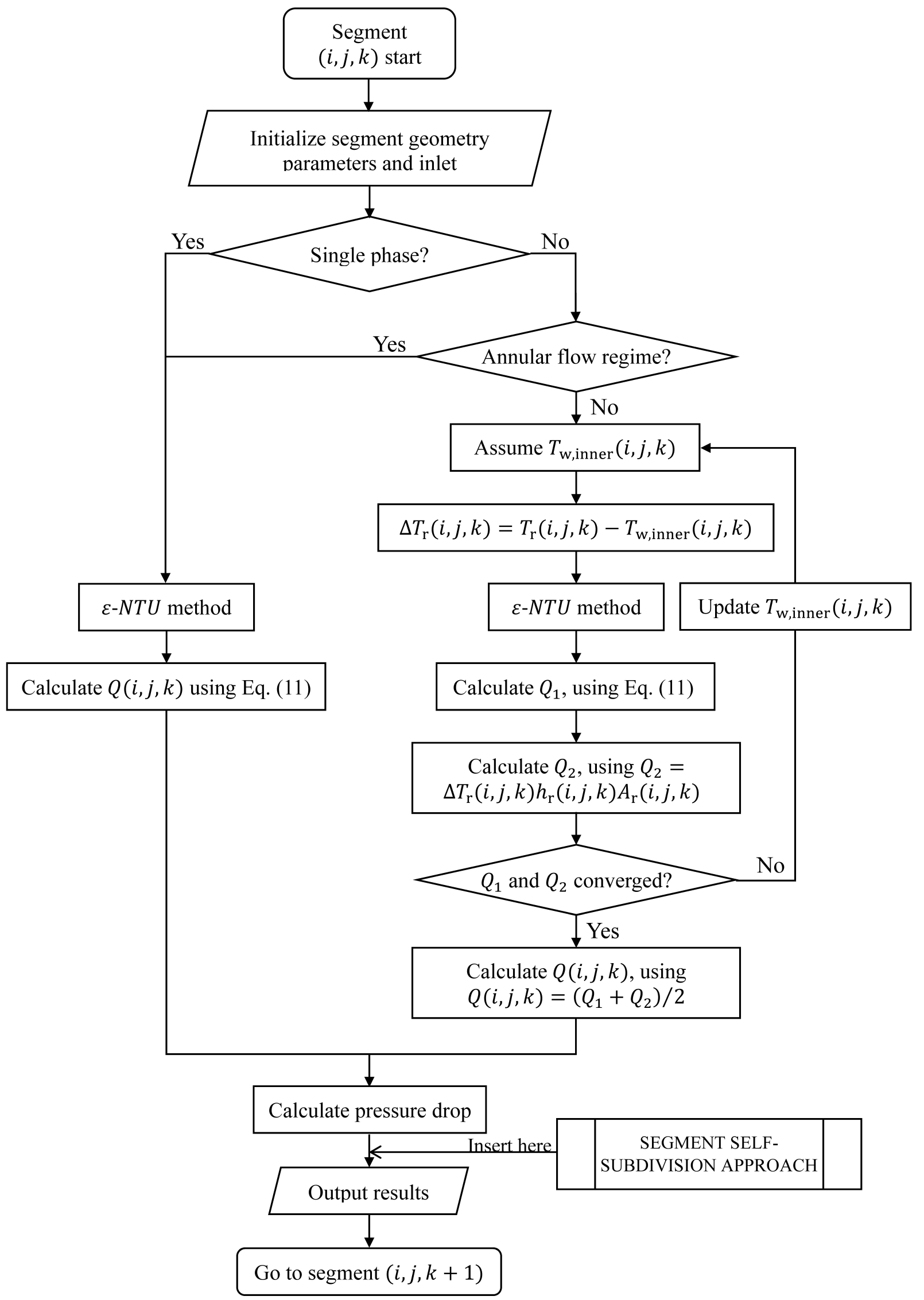




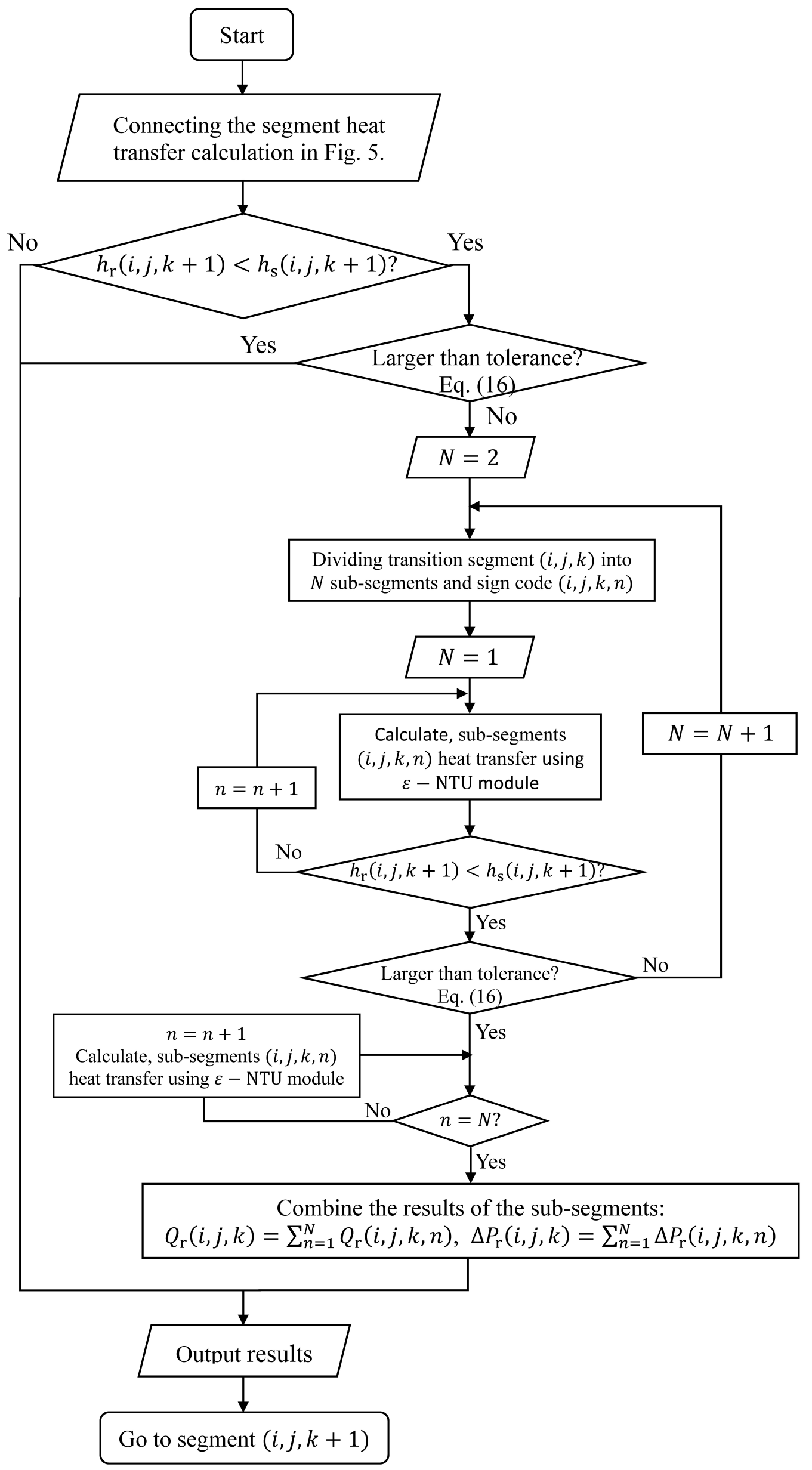




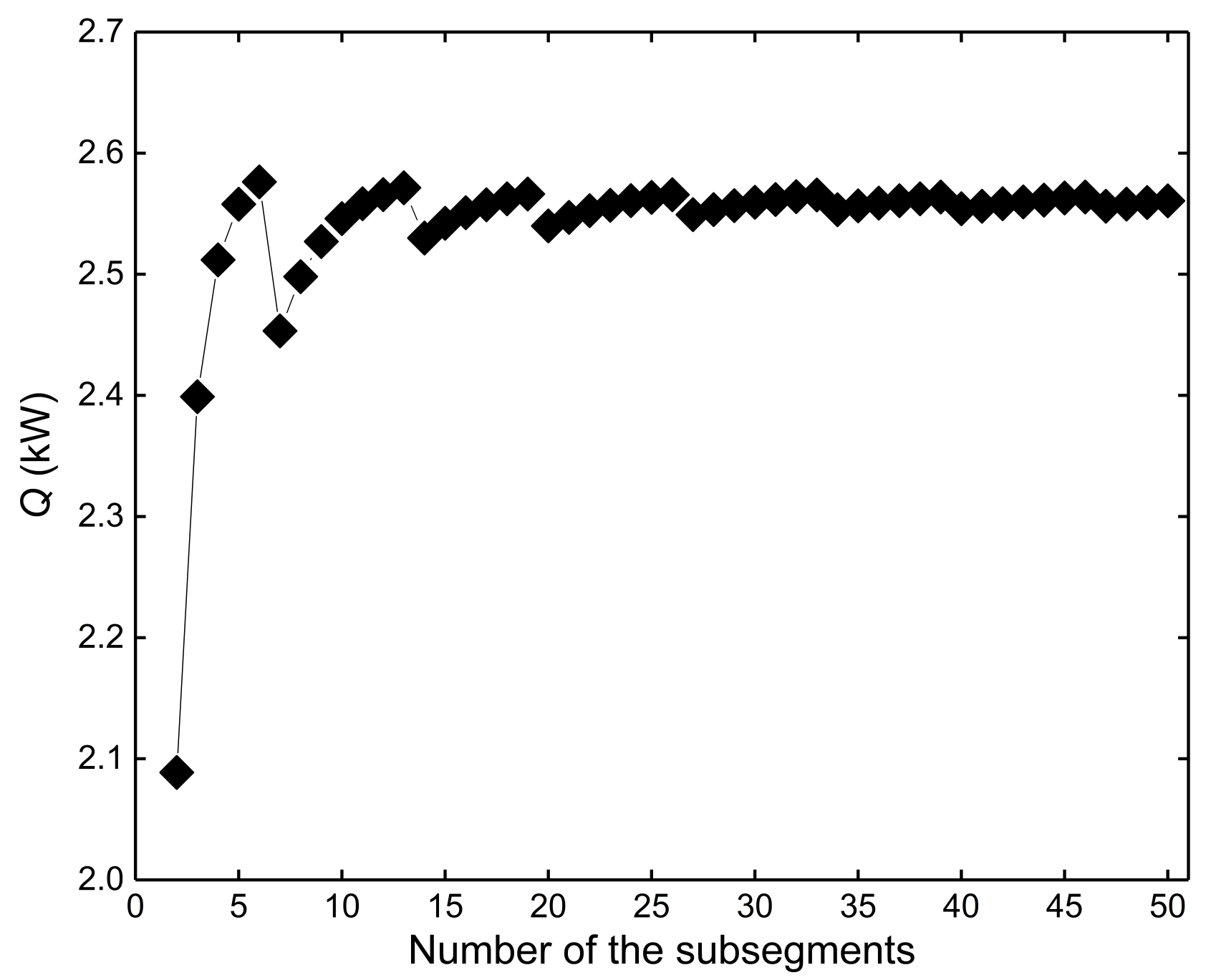




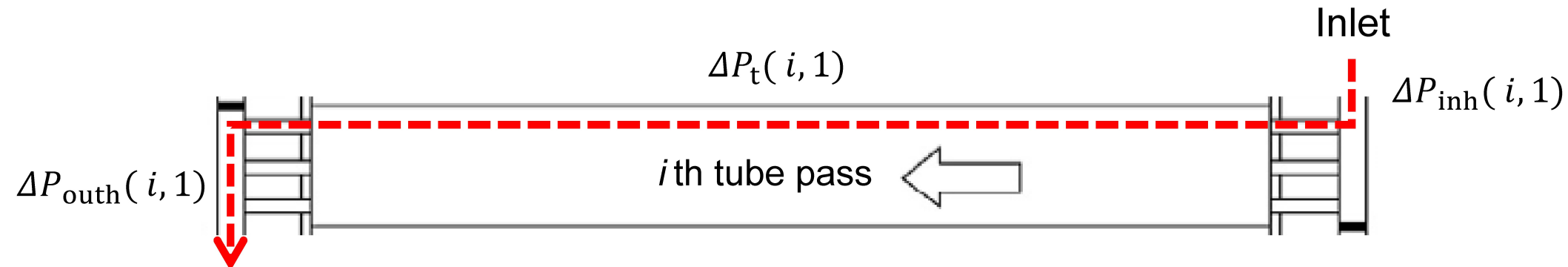

Outlet

The 1st Flow Path In the $i$ th Tube Pass

Inlet

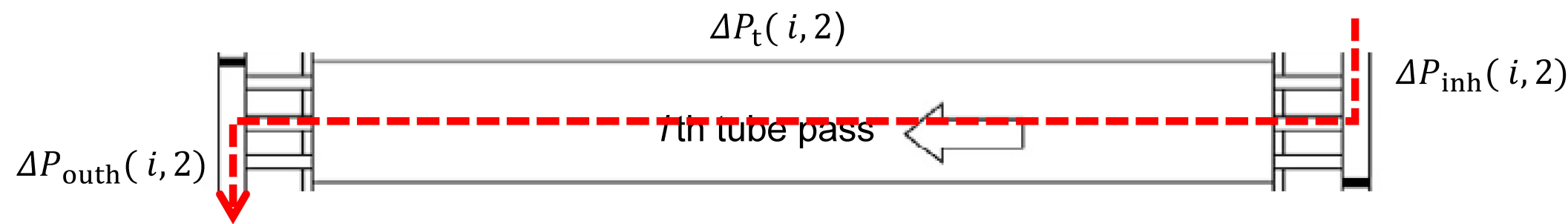

Outlet

The 2nd Flow Path In the $i$ th Tube Pass

Inlet

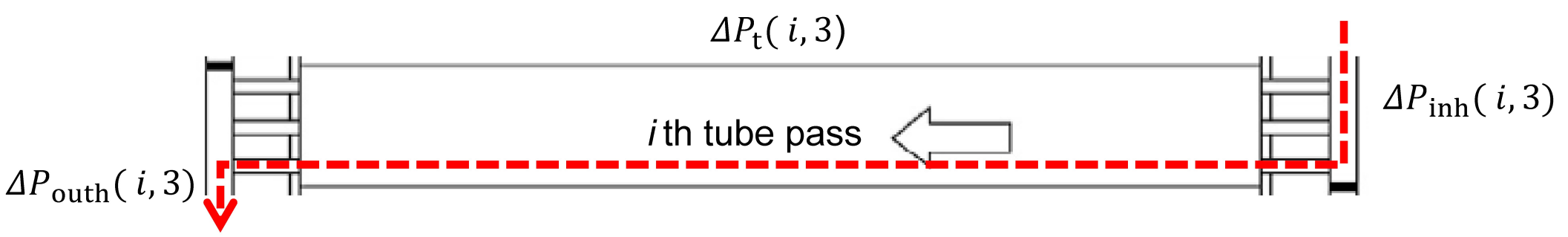

Outlet

The 3rd Flow Path In the $i$ th Tube Pass 


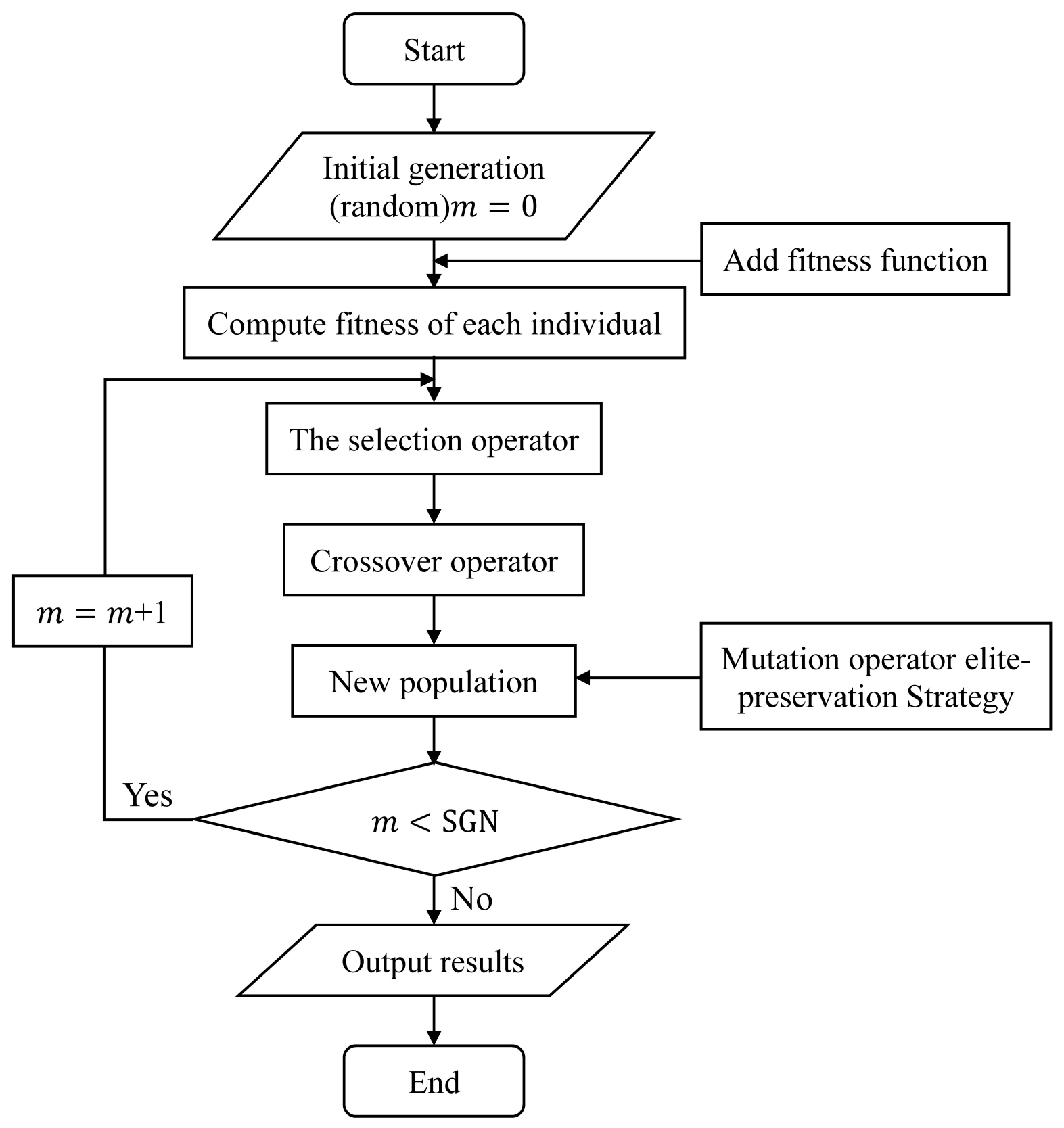


Population size: 1000

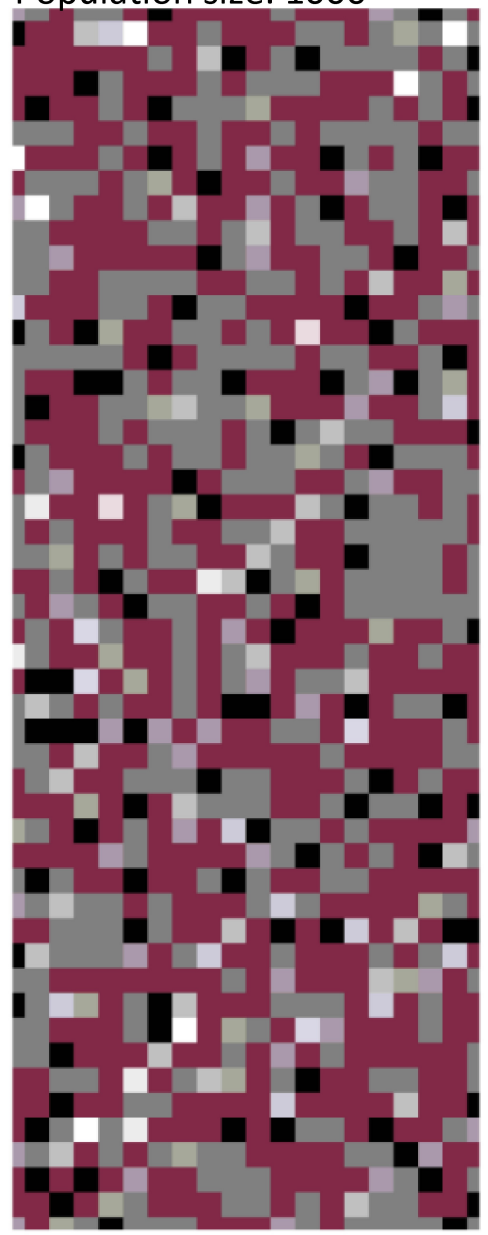

Initial generation

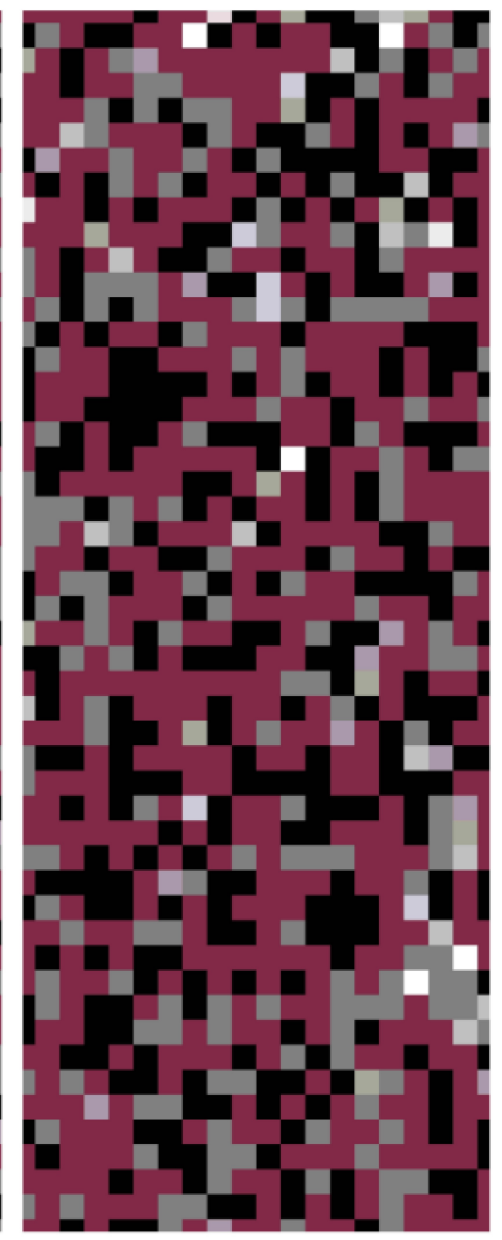

2nd generation

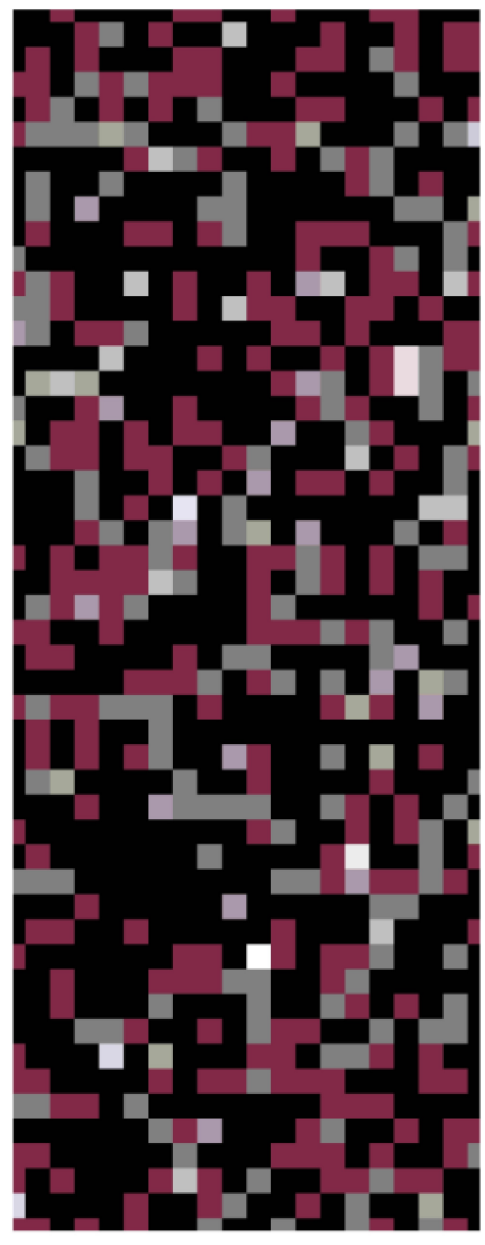

50th generation

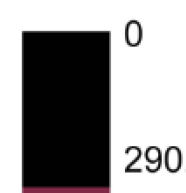

580.0

870.0

1160

1450

1740

2000

SD VALUE 


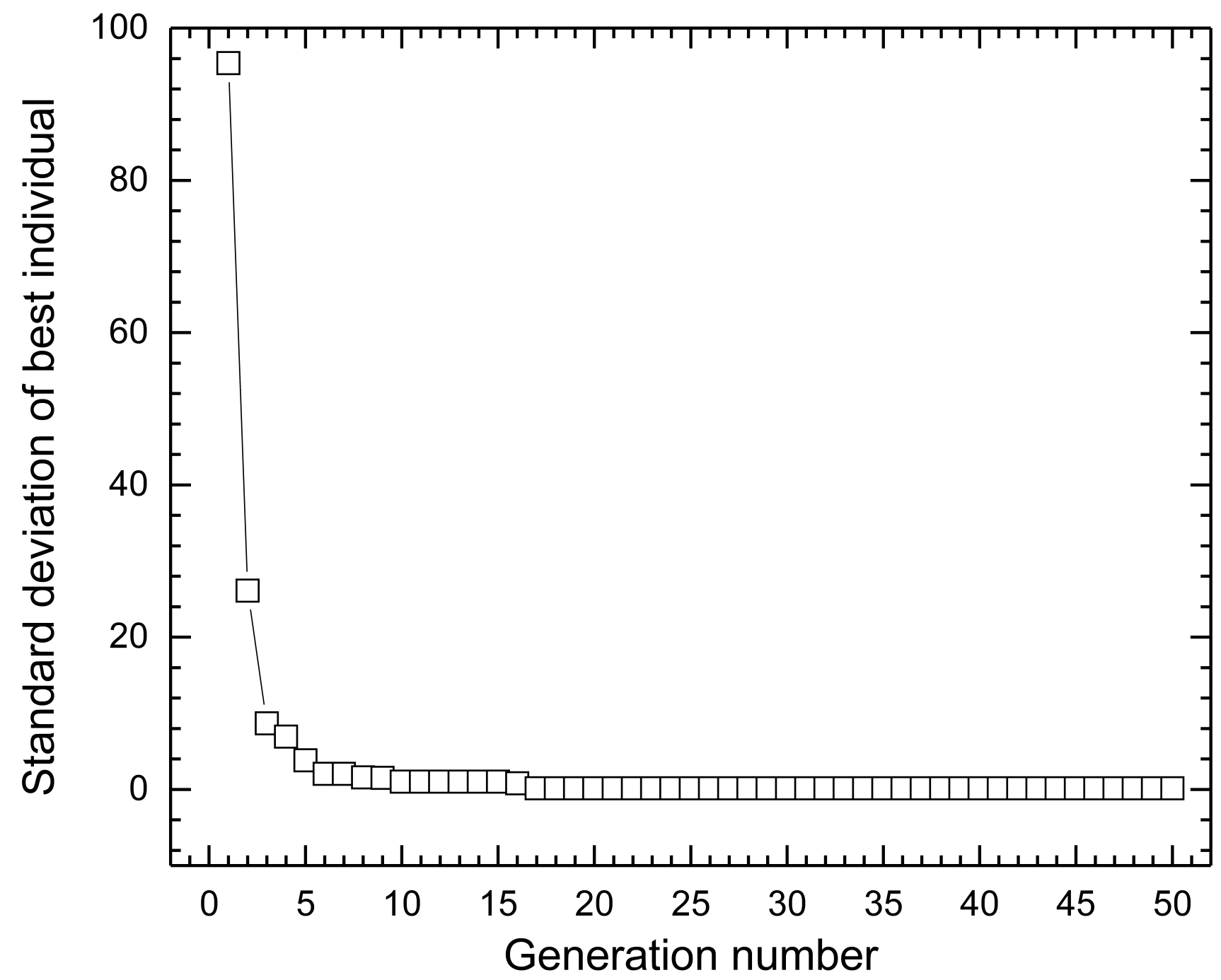




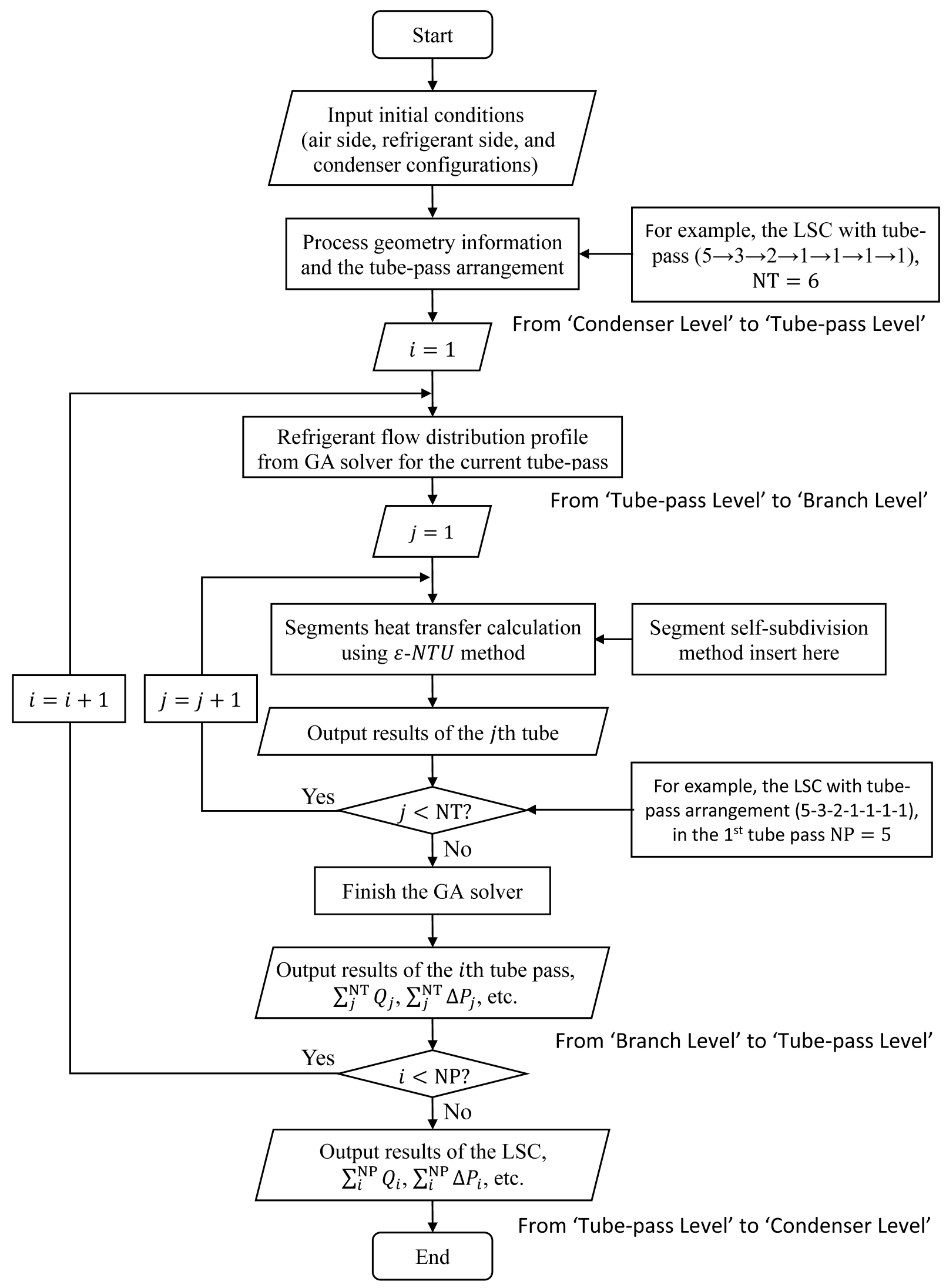




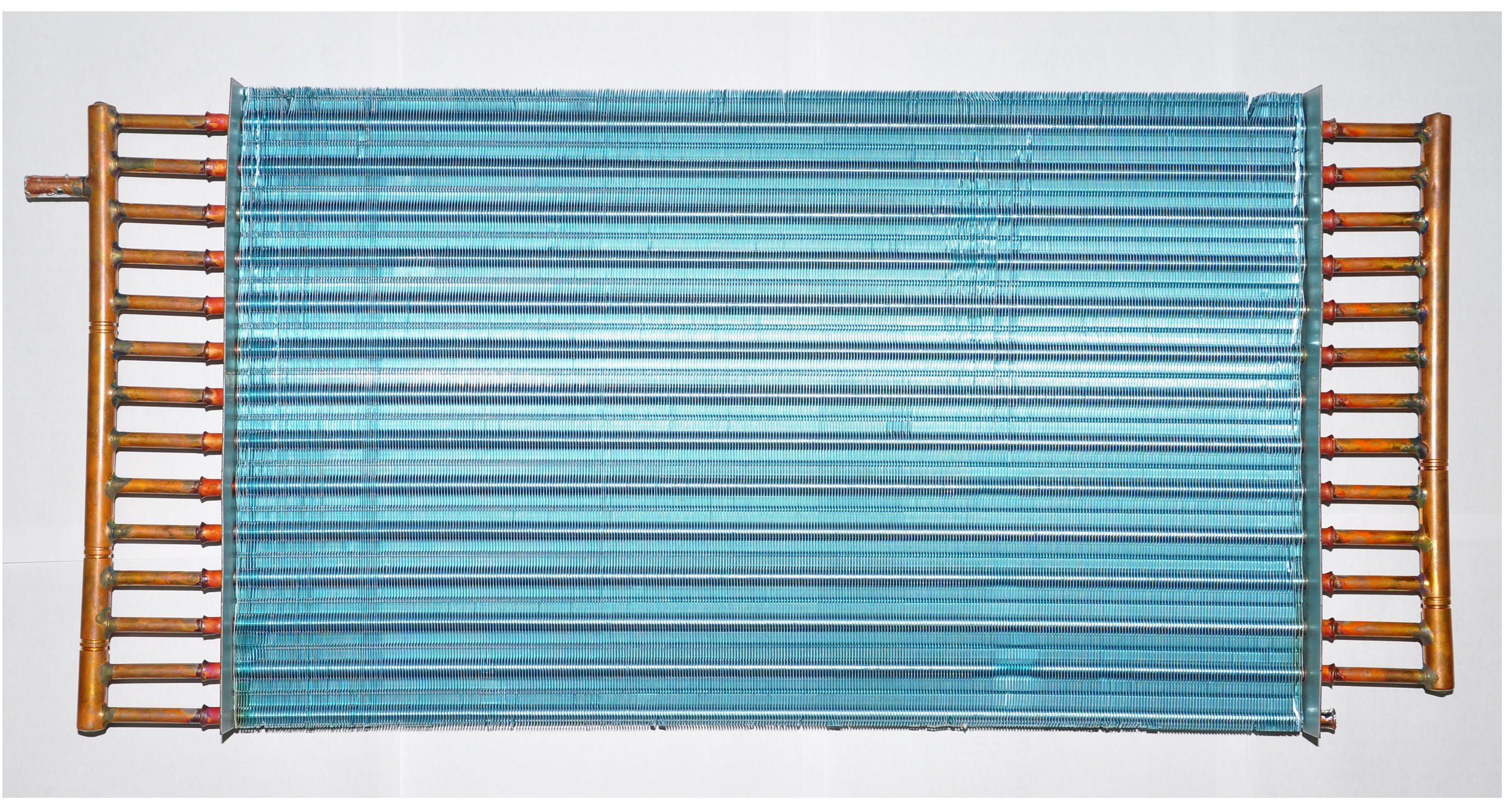




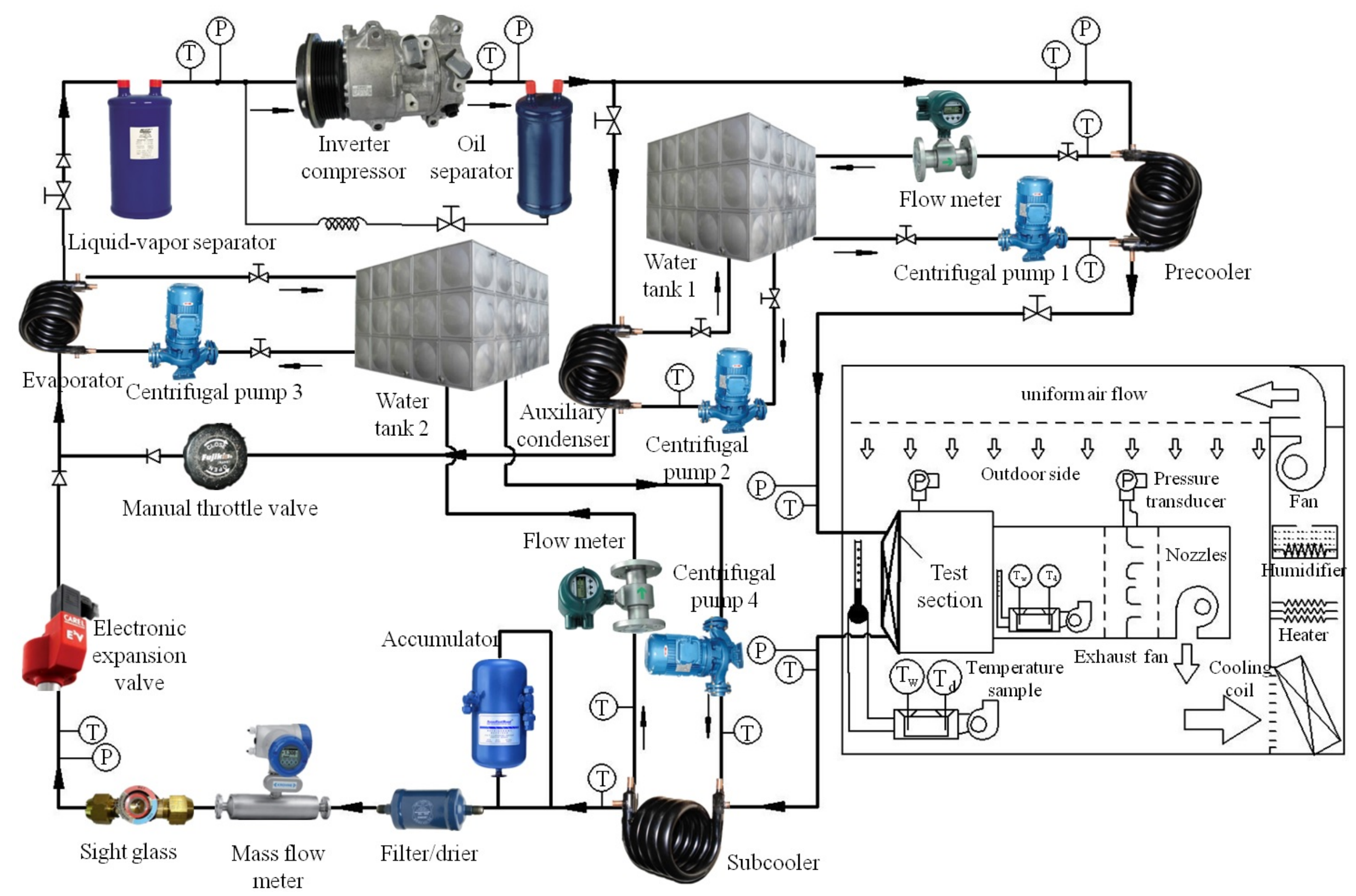




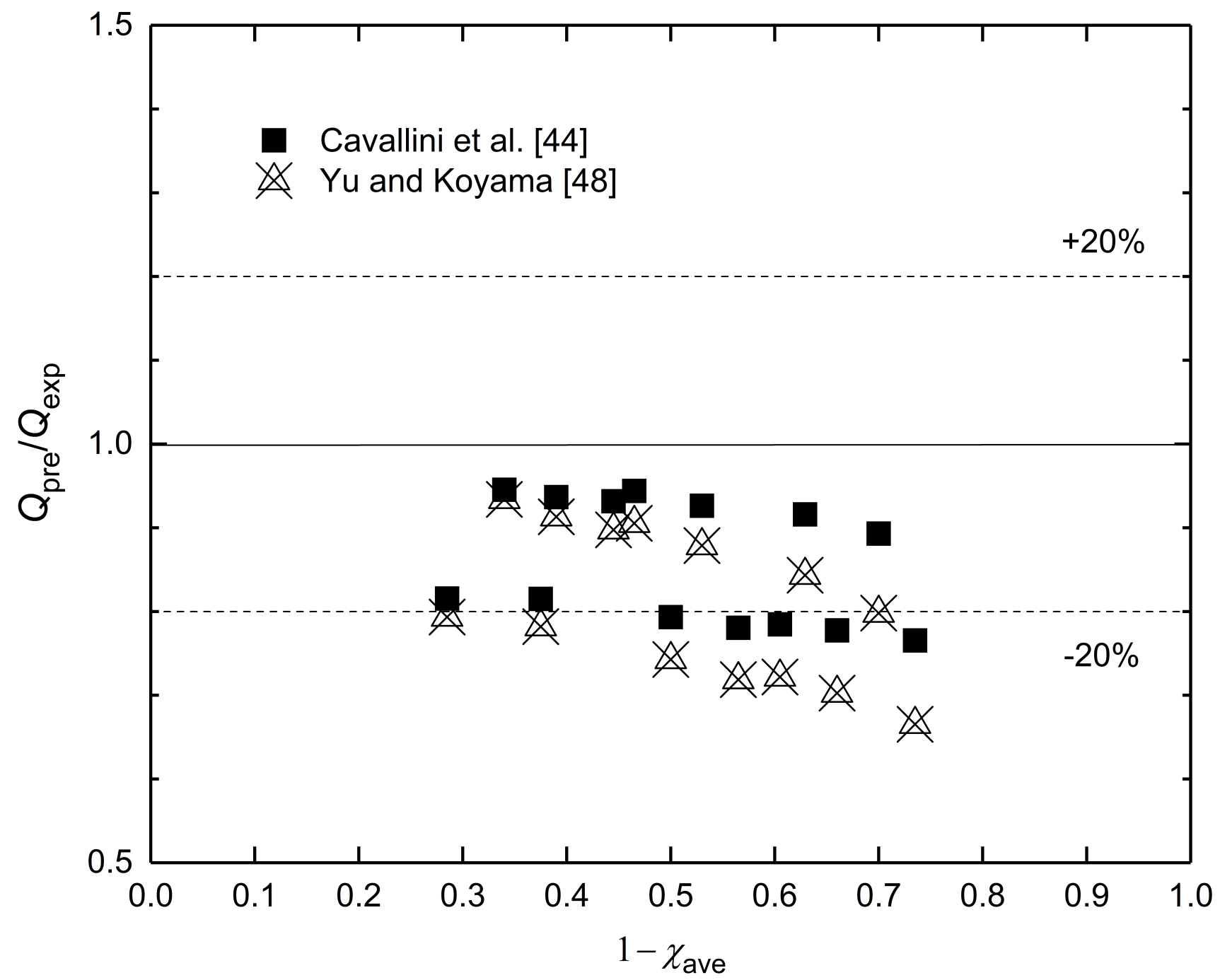




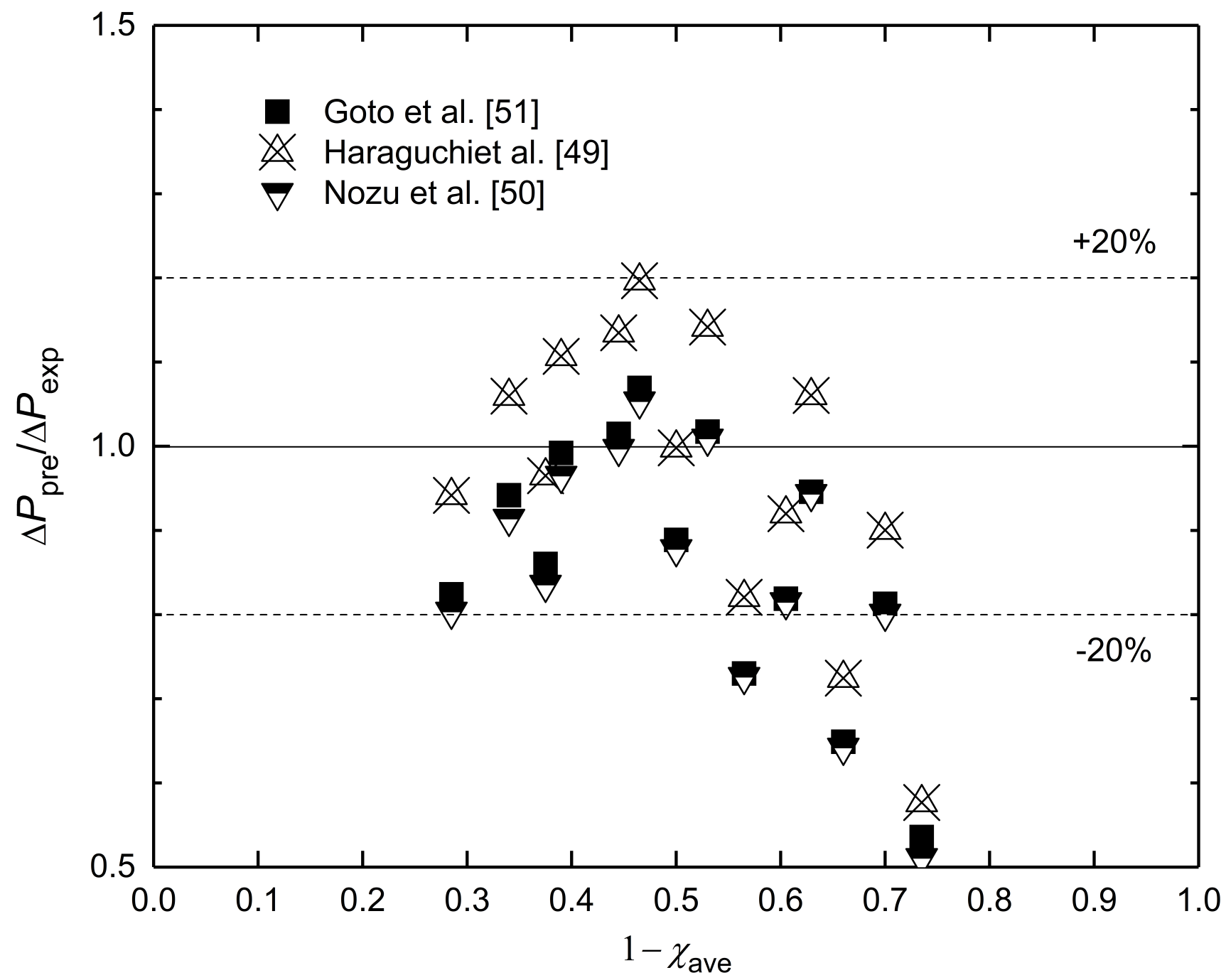




\section{Table captions}

Table 1 Summary of the models developed in in recent six years for simulation of airto-refrigerant heat exchangers

Table 2 Summary of the correlations used in the present work for prediction of the flow pattern map, heat transfer and pressure drop

Table 3 Configurations of the genetic algorithms

Table 4 Calculation results of the genetic algorithm stability

Table 5 Dimensions of the helical microfin tube

Table 6 Dimensions of the slit-louvred fin

Table 7 Details of the MPFCs-LS

Table 8 Accuracies of the instruments used to measure temperature, refrigerant flow rate, pressure and air flow rate

Table 9 Comparison of heat transfer capacity of a condenser between experimental data and predictions using empirical correlations

Table 10 Comparison of pressure drop of a condenser between experimental data and predictions using empirical correlations 
Table 1

Summary of the models developed in in recent six years for simulation of air-to-refrigerant heat exchangers

\begin{tabular}{|c|c|c|c|c|c|}
\hline Author & Methodology & Application & Fluid & RFMD & Comment \\
\hline Hua et al. [1] & $\begin{array}{l}\text { Tube-by-tube, } \\
\text { LMTD }\end{array}$ & $\begin{array}{l}\text { Fin-tube } \\
\text { condenser }\end{array}$ & R134a & No & $\begin{array}{l}\text { 1, MPFC-LS; } 2 \text { Optimize the tube-pass arrangement with the } \\
\text { penalty factor of two-phase evaluation criteria proposed by } \\
\text { Cavallini et al. [36]. }\end{array}$ \\
\hline Ren et al. [2] & $\begin{array}{l}\text { Port-segment, } \\
\text { Energy equation }\end{array}$ & PFMHX & $\begin{array}{l}\mathrm{R} 410 \mathrm{~A} \\
\mathrm{CO}_{2}\end{array}$ & Yes & $\begin{array}{l}\text { 1, Use fin theory; 2, Use T-junction phase separation theory } \\
\text { of Hwang et al. [34]; } 3 \text {, Use graph theory-based computation } \\
\text { algorithm for circuit calculation. }\end{array}$ \\
\hline Huang et al. [3] & $\begin{array}{l}\text { Port-segment, } \\
\varepsilon \text {-NTU method }\end{array}$ & PFMC & R134a & Yes & $\begin{array}{l}\text { Use the hybrid method which combines the CFD header } \\
\text { model and the } \varepsilon \text {-NTU based segmented microchannel tube } \\
\text { model. }\end{array}$ \\
\hline Huang et al. [4] & $\begin{array}{l}\text { Port-segment, } \\
\text { 3-stream AMTD }\end{array}$ & $\begin{array}{l}\text { PFMC } \\
\text { Gas-cooloer }\end{array}$ & Variety & $\begin{array}{l}\text { Yes } \\
\text { (Port-level) }\end{array}$ & Study the PFMC/Gas-cooler of various geometries. \\
\hline Zou et al. [5] & $\begin{array}{l}\text { Tube-segment, } \\
\varepsilon \text {-NTU method, }\end{array}$ & PFMHX & $\begin{array}{l}\mathrm{R} 134 \mathrm{a} \\
\mathrm{R} 410 \mathrm{~A}\end{array}$ & Yes & $\begin{array}{l}\text { 1, Use the quality distribution correlation based on their own } \\
\text { experimental data; 2, Mal-distributions resulting in the } \\
\text { capacity degradation are } 5 \% \text { for R } 124 \mathrm{a} \text { and } 30 \% \text { for R } 410 \mathrm{a} \text {. }\end{array}$ \\
\hline Hassan et al. [6] & $\begin{array}{l}\text { Finite segment, } \\
\text { Energy equation }\end{array}$ & PFME & $\begin{array}{l}\text { Not } \\
\text { specified }\end{array}$ & No & $\begin{array}{l}\text { 1, Use 2D fin model; 2, Combine segment by segment } \\
\text { approach with the SEWTLE method (Corberán et al. [35]). }\end{array}$ \\
\hline Joppolo et al. [7] & $\begin{array}{l}\text { Segment, } \\
\varepsilon \text {-NTU method }\end{array}$ & $\begin{array}{l}\text { Fin-tube } \\
\text { condenser }\end{array}$ & $\begin{array}{l}\text { Not } \\
\text { specified }\end{array}$ & Yes & $\begin{array}{l}\text { Analyze the impact of different circuit arrangements on heat } \\
\text { transfer rate, pressure drop, and refrigerant charge. }\end{array}$ \\
\hline Li and Hrnjak [8] & $\begin{array}{l}\text { Tube-segment, } \\
\varepsilon \text {-NTU method }\end{array}$ & PFME & $\begin{array}{l}\mathrm{R} 134 \mathrm{a} \\
\mathrm{R} 410 \mathrm{~A}\end{array}$ & Yes & $\begin{array}{l}\text { Present a method to quantify the distribution of liquid } \\
\text { refrigerant mass flow rate from infrared images. }\end{array}$ \\
\hline Liang et al. [9] & $\begin{array}{l}\text { Port-segment, } \\
\varepsilon \text {-NTU method }\end{array}$ & PFMC & $\mathrm{R} 134 \mathrm{a}$ & Yes & $\begin{array}{l}\text { 1, The PFMC with shorter louvred fins has higher heat } \\
\text { capacity by } 3 \% \sim 8.6 \% ; 2 \text {, Study models use several }\end{array}$ \\
\hline
\end{tabular}




\begin{tabular}{|c|c|c|c|c|c|}
\hline Wang et al. [10] & $\begin{array}{l}\text { Tube-segment, } \\
\text { AMTD }\end{array}$ & PFMC & $\mathrm{R} 134 \mathrm{a}$ & Yes & $\begin{array}{l}\text { correlations. } \\
\text { The effects of aspect ratio, tube-pass arrangement, anc } \\
\text { refrigerant mass flow rate on the RFMD are investigated. }\end{array}$ \\
\hline Yin et al. [11] & $\begin{array}{l}\text { Tube-segment, } \\
\varepsilon \text {-NTU method }\end{array}$ & PFMC & $\mathrm{R} 410 \mathrm{~A}$ & Yes & $\begin{array}{l}\text { 1, Compare the one-slab and two-slab PFMCs; } 2 \text {, Optimize } \\
\text { the tube-pass configurations. }\end{array}$ \\
\hline Datta et al. [12] & $\begin{array}{l}\text { Port-segment, } \\
\text { 3-stream AMTD }\end{array}$ & PFMC & $\mathrm{R} 134 \mathrm{a}$ & $\begin{array}{l}\text { Yes } \\
\text { (Port-level) }\end{array}$ & $\begin{array}{l}\text { Experimental and numerical study of the PFMC using } \\
\text { different types of blockages at the air side. }\end{array}$ \\
\hline $\begin{array}{l}\text { Shojaeefard and } \\
\text { Zare [13] }\end{array}$ & $\begin{array}{l}\text { Tube-segment, } \\
\varepsilon \text {-NTU method }\end{array}$ & PFME & $\mathrm{R} 134 \mathrm{a}$ & No & The model is used in multi-objective optimization procedure \\
\hline Tian et al. [14] & $\begin{array}{l}\text { Tube-segment, } \\
\text { AMTD }\end{array}$ & PFME & $\mathrm{R} 134 \mathrm{a}$ & No & $\begin{array}{l}\text { 1, Introduce a new flow boiling heat transfer correlation; } 2 \\
\text { Compare model results of various correlations. }\end{array}$ \\
\hline Zou et al. [15] & $\begin{array}{l}\text { Tube-segment, } \\
\varepsilon \text {-NTU method }\end{array}$ & $\begin{array}{l}\text { Fin-tube HX } \\
\text { PFMC/PFME }\end{array}$ & $\begin{array}{l}\mathrm{R} 134 \mathrm{a} \\
\mathrm{R} 410 \mathrm{~A}\end{array}$ & Yes & $\begin{array}{l}\text { 1, Quantify the liquid flow rate distribution based on the } \\
\text { infrared images; } 2 \text {, Compare two methods to simulate the we } \\
\text { air condition. }\end{array}$ \\
\hline Li et al. [16] & $\begin{array}{l}\text { Port-segment, } \\
\varepsilon \text {-NTU method }\end{array}$ & PFMHX & $\mathrm{R} 410 \mathrm{~A}$ & $\begin{array}{l}\text { Yes } \\
\text { (Port-level) }\end{array}$ & $\begin{array}{l}\text { The PFMHX capacity reduction resulting from the port-leve } \\
\text { flow mal-distribution is } 3.66 \% \text {. }\end{array}$ \\
\hline $\begin{array}{l}\text { Shojaeefard et al. } \\
{[17-18]}\end{array}$ & $\begin{array}{l}\text { Tube-segment, } \\
\varepsilon \text {-NTU method }\end{array}$ & PFMC & $\mathrm{R} 134 \mathrm{a}$ & Yes & $\begin{array}{l}\text { 1, Implement the hybrid method; } 2 \text {, Study the effects of tube } \\
\text { protrusion depth and inlet tube location on the RFMD. }\end{array}$ \\
\hline
\end{tabular}


Table 2

Summary of the correlations used in the present work for prediction of the flow pattern map, heat transfer and pressure drop

\begin{tabular}{|c|c|c|}
\hline Fluid & Type & Source \\
\hline \multirow{5}{*}{$\begin{array}{l}\text { Refrigerant side of } \\
\text { microfin tubes } \\
\text { (two phases in heat } \\
\text { transfer tubes) }\end{array}$} & $\begin{array}{l}\text { Heat transfer (Annular flow } \\
\text { regime) }\end{array}$ & $\begin{array}{l}\text { Yu and Koyama [48]; } \\
\text { Cavallini et al. [44] }\end{array}$ \\
\hline & $\begin{array}{l}\text { Frictional pressure drop (Annular } \\
\text { flow regime) }\end{array}$ & $\begin{array}{l}\text { Haraguchi et al. [49]; } \\
\text { Nozu et al. [50]; } \\
\text { Goto et al. [51]; }\end{array}$ \\
\hline & $\begin{array}{l}\text { Heat transfer (Stratified-wave } \\
\text { flow regime) }\end{array}$ & Kim et al. [45] \\
\hline & $\begin{array}{l}\text { Frictional pressure drop } \\
\text { (Stratified-wave flow regime) }\end{array}$ & Kim et al. [45] \\
\hline & $\begin{array}{l}\text { Evaluation of the Annular flow } \\
\text { and Stratified-wave flow regimes }\end{array}$ & Cavallini et al. [44] \\
\hline \multirow{2}{*}{$\begin{array}{l}\text { Refrigerant side of } \\
\text { microfin tubes } \\
\text { (single phase in } \\
\text { heat transfer tubes) }\end{array}$} & Heat transfer & Wu et al. [52] \\
\hline & Pressure drop & Wu et al. [52] \\
\hline \multirow{3}{*}{$\begin{array}{l}\text { Refrigerant side of } \\
\text { smooth tubes } \\
\text { (two phases in the } \\
\text { headers) }\end{array}$} & Fractional pressure drops & Friedel [53] \\
\hline & $\begin{array}{l}\text { Gravitational pressure drops, } \\
\text { contraction, and expansion losses }\end{array}$ & Collier and Thome [54] \\
\hline & Void fraction of vertical tubes & $\begin{array}{l}\text { Rouhani and Axelsson } \\
\text { [55] }\end{array}$ \\
\hline $\begin{array}{l}\text { Refrigerant side of } \\
\text { smooth tubes }\end{array}$ & $\begin{array}{l}\text { Fractional pressure drops and } \\
\text { gravitational pressure drops }\end{array}$ & Thome [56] \\
\hline $\begin{array}{l}\text { (single phase in the } \\
\text { headers) }\end{array}$ & Contraction and expansion losses & Shah and Sekulic [57] \\
\hline $\begin{array}{l}\text { Refrigerant side of } \\
\text { the headers }\end{array}$ & Minor loss due to tube protrusion & Yin et al. [58] \\
\hline $\begin{array}{l}\text { Air side of slit- } \\
\text { louvre fin }\end{array}$ & Heat transfer and pressure drop & Wang et al. [59] \\
\hline
\end{tabular}


Table 3

Configurations of the genetic algorithms

\begin{tabular}{ll}
\hline Parameter & Value \\
\hline Fitness function & The standard deviation $(\mathrm{SD})$ \\
Chromosome vector & {$\left[G_{(1)}, \ldots, G_{(i)}, \ldots, G_{(\mathrm{NT})}\right]$} \\
Population size & 1000 \\
Crossover probability & 0.4 \\
Mutation probability & 0.2 \\
Elite count & 10 \\
Stop generation number $(\mathrm{SGN})$ & 50 \\
\hline
\end{tabular}


Table 4

Calculation results of the genetic algorithm stability

\begin{tabular}{lcccccc}
\hline $\begin{array}{l}\text { Calculation } \\
\text { times }\end{array}$ & $\mathrm{SD}$ & $G_{1}$ & $G_{2}$ & $G_{3}$ & $G_{4}$ & $G_{5}$ \\
\hline 1st & 0.0017 & 125.9679 & 130.4252 & 107.9614 & 106.2003 & 115.8120 \\
2nd & 0.0045 & 125.9677 & 130.4247 & 107.9620 & 106.2000 & 115.8123 \\
3rd & 0.0027 & 125.9681 & 130.4247 & 107.9613 & 106.2005 & 115.8119 \\
4th & 0.0060 & 125.9687 & 130.4241 & 107.9617 & 106.2004 & 115.8119 \\
5th & 0.0041 & 125.9678 & 130.4250 & 107.9615 & 106.2007 & 115.8115 \\
Relative error & 0.0038 & 0.000395 & 0.000403 & 0.000264 & 0.000274 & 0.000267 \\
\hline
\end{tabular}


Table 5

Dimensions of the helical microfin tube

\begin{tabular}{cccccccc}
\hline $\begin{array}{c}D_{\mathrm{o}} \\
\mathrm{mm}\end{array}$ & $\begin{array}{c}d_{\mathrm{i}} \\
\mathrm{mm}\end{array}$ & $\begin{array}{c}p_{\mathrm{t}} \\
\mathrm{mm}\end{array}$ & $\begin{array}{c}h_{\mathrm{f}} \\
\mathrm{mm}\end{array}$ & $\begin{array}{c}t_{\mathrm{b}} \\
\mathrm{mm}\end{array}$ & $\begin{array}{c}\beta \\
\mathrm{deg}\end{array}$ & $\begin{array}{c}\gamma \\
\mathrm{deg}\end{array}$ & $N_{\mathrm{mf}}$ \\
\hline 7.37 & 6.89 & 0.408 & 0.15 & 0.14 & 53 & 18 & 60 \\
\hline
\end{tabular}


Table 6

Dimensions of the slit-louvred fin

\begin{tabular}{cccccccc}
\hline $\begin{array}{c}F_{\mathrm{s}} \\
\mathrm{mm}\end{array}$ & $\begin{array}{c}\delta_{\mathrm{f}} \\
\mathrm{mm}\end{array}$ & $\begin{array}{c}P_{1} \\
\mathrm{~mm}\end{array}$ & $\begin{array}{c}S_{\mathrm{s}} \\
\mathrm{mm}\end{array}$ & $\begin{array}{c}S_{\mathrm{h}} \\
\mathrm{mm}\end{array}$ & $S_{\mathrm{n}}$ & $N_{\mathrm{r}}$ & $N_{\mathrm{f}}$ \\
\hline 1.35 & 0.115 & 12.7 & 1.2 & 1.0 & 6 & 1 & 365 \\
\hline
\end{tabular}


Table 7

Details of the MPFCs-LS

\begin{tabular}{ll}
\hline Parameter & Value \\
\hline Tube-pass arrangement & $5 \rightarrow 3 \rightarrow 2 \rightarrow 1 \rightarrow 1 \rightarrow 1 \rightarrow 1$ \\
Helical microfin tube material & Copper \\
Tube length $L, \mathrm{~mm}$ & 490 \\
Tube pitch $P_{\mathrm{t}}, \mathrm{mm}$ & 21 \\
Tube number $N_{\mathrm{t}}$ & 14 \\
Inlet pipe position $P_{\text {inlet, }} \mathrm{mm}$ & $1.5 \times P_{\mathrm{t}}$ to top \\
Slit- louvred fin material & Aluminum \\
\hline
\end{tabular}


Table 8

Accuracies of the instruments used to measure temperature, refrigerant flow rate, pressure and air flow rate

\begin{tabular}{lll}
\hline Instrument & Accuracy & Range \\
Pt100 platinum resistance thermometer & $0.15 \mathrm{~K}$ & -50 to $200{ }^{\circ} \mathrm{C}$ \\
Coriolis mass flow meter & $0.15 \%$ & 0 to $12 \mathrm{~kg} / \mathrm{min}$ \\
Magnetic flow meter & $0.35 \%$ f.s. & 0 to $6.361 \mathrm{~m}^{3} / \mathrm{h}$ \\
Strain-gage pressure transducer & $0.2 \%$ f.s. & 0 to $4 \mathrm{MPa}$ \\
Micro differential pressure transmitter & $0.2 \%$ f.s. & 0 to $800 \mathrm{~Pa}$ \\
\hline
\end{tabular}


Table 9

Comparison of heat transfer capacity of a condenser between experimental data and predictions using empirical correlations

\begin{tabular}{cccccccc}
\hline & & \multicolumn{4}{c}{ Yu \& } & \multicolumn{2}{c}{ Cavallini et al. } \\
$\begin{array}{cccccc}G \\
\mathrm{~kg} / \mathrm{m}^{2} \mathrm{~s}\end{array}$ & $\begin{array}{c}T_{\text {sat }} \\
{ }^{\circ} \mathrm{C}\end{array}$ & $\begin{array}{c}Q \\
\mathrm{~W}\end{array}$ & $\chi_{\text {ave }}$ & \multicolumn{2}{c}{ Koyama } & \multicolumn{2}{c}{$[44]$} \\
& & & & a.m. & r.m.s. & a.m. & r.m.s. \\
\hline 533 & 45 & 1525 & $0.30 \sim 0.66$ & -11.9 & 12.6 & 7.2 & 7.4 \\
533 & 45 & 1125 & $0.27 \sim 0.72$ & -0.7 & 5.7 & 7.1 & 7.5 \\
\hline
\end{tabular}


Table 10

Comparison of pressure drop of a condenser between experimental data and predictions using empirical correlations

\begin{tabular}{|c|c|c|c|c|c|c|c|c|c|}
\hline \multirow{2}{*}{$\begin{array}{c}G \\
\mathrm{~kg} / \mathrm{m}^{2} \mathrm{~s}\end{array}$} & \multirow{2}{*}{$\begin{array}{l}T_{\text {sat }} \\
{ }^{\circ} \mathrm{C}\end{array}$} & \multirow{2}{*}{$\begin{array}{c}Q \\
\mathrm{~W}\end{array}$} & \multirow{2}{*}{$\chi_{\text {ave }}$} & \multicolumn{2}{|c|}{$\begin{array}{c}\text { Haraguchi et al. } \\
\text { [49] }\end{array}$} & \multicolumn{2}{|c|}{$\begin{array}{c}\text { Nozu et al. } \\
{[50]}\end{array}$} & \multicolumn{2}{|c|}{$\begin{array}{c}\text { Goto et al. } \\
\text { [51] }\end{array}$} \\
\hline & & & & & & $\mathrm{m}$. & $\begin{array}{c}\text { r.m.s } \\
.\end{array}$ & a.m. & r.m.s \\
\hline 533 & 45 & 1525 & 0.66 & 8.6 & 12.3 & -4.5 & 8.8 & -2.9 & 8.2 \\
\hline 533 & 45 & 1125 & $0.27 \sim 0.72$ & -15.1 & 20.6 & -25.5 & 28.2 & -24.2 & 26.9 \\
\hline
\end{tabular}


The authors declared that there is no conflict of interest. 